\title{
Computational replication of the patient-specific stenting procedure for coronary artery bifurcations: from OCT and CT imaging to structural and hemodynamics analyses
}

Claudio Chiastra ${ }^{\mathbf{1}, \mathbf{2}}$, Wei $\mathrm{Wu}^{\mathbf{1}}$, Benjamin Dickerhoff ${ }^{\mathbf{3}}$, Ali Aleiou ${ }^{\mathbf{3}}$, Gabriele Dubini ${ }^{\mathbf{1}}$, Hiromasa Otake $^{4}$, Francesco Migliavacca ${ }^{1}$, John F. LaDisa Jr., 


\section{ABSTRACT}

The optimal stenting technique for coronary artery bifurcations is still debated. With additional advances computational simulations can soon be used to compare stent designs or strategies based on verified structural and hemodynamics results in order to identify the optimal solution for each individual's anatomy. In this study, patient-specific simulations of stent deployment were performed for 2 cases to replicate the complete procedure conducted by interventional cardiologists. Subsequent computational fluid dynamics (CFD) analyses were conducted to quantify hemodynamics quantities linked to restenosis.

Patient-specific pre-operative models of coronary bifurcations were reconstructed from CT angiography and optical coherence tomography (OCT). Plaque location and composition were estimated from OCT and assigned to models, and structural simulations were performed in Abaqus. Artery geometries after virtual stent expansion of Xience Prime or Nobori stents created in SolidWorks were compared to post-operative geometry from OCT and CT before being extracted and used for CFD simulations in SimVascular. Inflow boundary conditions based on body surface area, and downstream vascular resistances and capacitances were applied at branches to mimic physiology.

Artery geometries obtained after virtual expansion were in good agreement with those reconstructed from patient images. Quantitative comparison of the distance between reconstructed and post-stent geometries revealed a maximum difference in area of $20.4 \%$. Adverse indices of wall shear stress were more pronounced for thicker Nobori stents in both patients. These findings verify structural analyses of stent expansion, introduce a workflow to combine software packages for solid and fluid mechanics analysis, and underscore important stent design features from prior idealized studies. The proposed approach may ultimately be useful in determining an optimal choice of stent and position for each patient. 6 (1) 8 69 0 1 2

3 Keywords: mathematical model, finite element analysis, computational fluid dynamics, coronary bifurcation, stent 


\section{INTRODUCTION}

The treatment of complex coronary lesions such as bifurcation lesions remains a challenge in interventional cardiology because of lower success rates and higher restenosis rates as compared to non-complex lesions (Lassen et al., 2014). Since the introduction of drug eluting stents in 2004, restenosis rate after stent implantation have fallen below $10 \%$ in several randomized clinical trials (Dangas et al., 2010). However, this rate increases when coronary bifurcation lesions are treated (Lemos et al., 2004; Mauri et al., 2008; Zahn et al., 2005).

The optimal stenting technique for treating diseased coronary bifurcations is still debated without a consensus among interventional cardiologists (Lassen et al., 2014). Indeed, the postoperative follow-up is influenced by different factors such as stent design (Morton et al., 2004; Timmins et al., 2011, 2008), the use of one or two stents (Katritsis et al., 2009; Zhang et al., 2009), plaque morphology and composition (Timmins et al., 2008), arterial injury caused by stent deployment (Kornowski et al., 1998; Schwartz et al., 1992), and adverse hemodynamics induced by the stent struts protruding inside the lumen (Foin et al., 2014). A number of studies proved that neointima thickening (NT), which can lead to in-stent restenosis, is related to increased wall stress post-stenting (Timmins et al., 2011) and to altered local fluid dynamics (e.g. low and oscillating wall shear stress; WSS) provoked by the stent presence within the coronary artery (LaDisa Jr. et al., 2005; Malek et al., 1999).

In this context, virtual simulations of patient-specific coronary bifurcation stenting can be used to compare the effect of different stent designs or stenting strategies on structural and fluid dynamics results in order to identify the optimal solution for each individual's anatomy (Migliavacca et al., 2015). In several previous studies (Chiastra et al., 2013; Ellwein et al., 2011; Gundert et al., 2011; Morlacchi et al., 2013; Mortier et al., 2015) patient-specific structural and fluid dynamic simulations were conducted. However, the post-operative geometry obtained after virtual stent deployment was rarely compared with the in vivo post-operative images (Morlacchi et al., 2013). Moreover, when performed, this comparison is often qualitative and based only on computed tomography (CT) and angiography data. The use of optical coherence tomography (OCT) images allows better model verification, because of its high spatial resolution compared to CT and angiography (Farooq et al., 2009; Ferrante et al., 2013).

In this study patient-specific simulations of stent deployment are performed to replicate the complete procedure followed by clinicians to treat coronary bifurcations. OCT and CT images are used to reconstruct the 3D models of the coronary bifurcations. The reliability of structural finiteelement analyses (FEA) in predicting post-operative geometric outcomes is evaluated. Subsequent computational fluid dynamics (CFD) analyses are conducted to quantify the influence of local 
hemodynamics variables (e.g. indices of WSS). Different stent designs and stent positioning within the patient-specific models are studied to explore potential post-operative scenarios.

\section{MATERIALS AND METHODS}

\subsection{Imaging and reconstruction of artery morphology and composition}

Accurate reconstruction of artery geometry is critical to the patient-specific modeling process, and depends on imaging resolution. This study used a hybrid approach of CT angiography and OCT to reconstruct artery geometry within the stented region by mathematically determining the location of the OCT imaging wire during image acquisition (Ellwein et al., 2011). These method combines conventional and invasive high-resolution imaging modalities (Fig.1A). We refer to the use of CT and OCT data with this approach as Hybrid $O C$ - CT (see details below).

This investigation was approved by the ethics committees of all participating institutions. Informed consent was obtained for the use of data in this study. Coronary angiography, CT and OCT imaging were performed before (i.e. pre-PCI) and immediately after stenting (i.e. post-stent) as previously reported (Otake et al., 2009). OCT images were acquired and quantified as discussed elsewhere (Ellwein et al., 2011; Nakazato et al., 2015).

Separate pre-PCI and post-stenting lumen models were created for two patients (namely, Cases 1 and 2). Case 1 consisted of a left anterior descending/first diagonal (LAD/D1) bifurcation of a 70year-old female while Case 2 is a left circumflex artery (LCX) with two branches of a 73 -year-old male. Pre-PCI lumen models were used to simulate local deformations caused by stenting from FEA (see details below). The post-stenting models were created to validate the accuracy of deformations from FEA. For both lumen models (i.e. pre-PCI and post-stenting), high resolution OCT segments were registered within the region of interest using Hybrid OC-CT (Ellwein et al., 2011). Briefly, OCT images were processed to isolate lumen contours in Matlab (MathWorks Inc., Natick, MA, USA). The wire pullback pathway (Fig.1A) was determined by minimizing total bending energy within the lumen volume delineated by CT. Lumen segments from OCT were then registered on the wire pathway using landmarks where possible. Remaining lumen segments were then positioned longitudinally according to OCT image spacing. All lumen segments were then oriented orthogonal to the wire pathway and rotated such that their centroids aligned with the artery centerline. The aligned and oriented lumen segments were loaded into SimVascular (simtk.org) for lofting and blending, thus obtaining lumen geometries (Fig.1A).

OCT data did not allow for measurement of wall thickness because of its reduced tissue penetration (Waksman et al., 2013). To create external arterial wall surfaces (Fig.1B), circumferential cross-sections orthogonal to lumen centerlines were smoothly connected using a 
lofting operation. These cross-sections were defined only in the regions where no plaques or symmetric atherosclerotic plaques were recognized by imaging in order to obtain a smooth external wall and locate potential asymmetric plaques (Morlacchi et al., 2013). A ratio between the arterial wall thickness and the healthy lumen as presented elsewhere (Holzapfel et al., 2005) was used to calculate the cross-sectional diameters. The arterial wall was meshed with $\sim 100,000$ eight-node cubic elements with reduced integration using ICEM CFD (ANSYS Inc., Canonsburg, PA, USA) (Fig.2A). The mesh density is comparable to that used in a previous work (Capelli et al., 2009) in which similar coronary artery models were implemented and numerically verified. An isotropic hyperplastic constitutive model based on a reduced polynomial strain energy density function of sixth order (Morlacchi et al., 2011) was implemented to describe the arterial wall material properties. The coefficients of the hyperelastic model (Table 1) were identified from the experimental results obtained on media layer specimens of human coronary arteries in the circumferential direction (Holzapfel et al., 2005).

Since the exact radial plaque position within the arterial wall could not be deduced by the patient images, a previously developed method for plaque identification (Morlacchi et al., 2013) was applied and extended (Fig.2A). First, a centerline was identified from the external wall surface. Second, the distance between this centerline and each element of the arterial wall was calculated in the radial direction. Lastly, a healthy radius was assumed based on angiography inspection of nonatherosclerotic locations. All elements with a distance less than the healthy radius (Fig.2A, black arrows) were considered as plaque. Both investigated cases resulted in a local maximum area stenosis of $\sim 70 \%$.

A different composition was then assigned to each region of plaque. To achieve this, a trained interventional cardiologist manually delineated different plaque regions by looking at each OCT slice and then delineating the plaque regions on the longitudinal view to convey where the different components were located (Fig.2B-C). In Case 1 the majority of the plaque was classified as soft (Fig.2B). In Case 2 the plaque was mainly stiff (i.e. fibrous plaque) with a small region of soft material (i.e. fibrous and lipid plaque) close to the proximal side branch (Fig.2C). Soft and stiff plaques were modeled using an isotropic hyperelastic law based on experimental data (Loree et al., $1994)$ with ideal plasticity to simulate rupture at the experimental tensile stress values $(\sim 400 \mathrm{kPa})$. The material parameters are listed in Table 1 . A density value of $1120 \mathrm{~kg} / \mathrm{m}^{3}$ was used for both arterial wall and plaques (Morlacchi et al., 2011).

\subsection{Stent and balloon models}


The commercially available Xience Prime (Abbott Laboratories, Abbott Park, IL, USA) and Nobori (Terumo, Somerset, NJ, USA) DES were considered in this study. The two stents are characterized by a different strut thickness (Table 2). Geometries were created using SolidWorks (Dassault Systèmes SolidWorks Corp., Waltham, MA, USA). Both stents are fabricated from a cobalt-chromium alloy that can be described by a von Mises-Hill plasticity model with isotropic hardening. The following material properties were assigned to the stent models during FEA: Young modulus (233 GPa), Poisson coefficient (0.35), yield stress (414 MPa), ultimate stress (933 MPa), deformation at break $(44.5 \%)$, and material density $\left(8000 \mathrm{~kg} / \mathrm{m}^{3}\right)$. The geometries were discretized with a highly regular hexahedral mesh of $\sim 120,000$ reduced integration cubic elements using HyperMesh software package (Altair Engineering, Troy, MI, USA).

Geometric models of angioplasty and stent delivery balloons were created in their crimped configuration using SolidWorks. The balloon thickness was $0.025 \mathrm{~mm}$. The polymeric material of the balloons was described using a linear elastic isotropic model with a Young modulus of 1.45 GPa and a Poisson coefficient of 0.3 . The balloon models were discretized with $\sim 25,000$ reduced integration membrane elements.

\subsection{Structural simulations of stent deployment}

The following virtual stent expansion simulations were performed in the coronary bifurcation models to replicate the real stenting procedure performed by the interventional cardiologists who treated the cases featured (Fig.3):

1) Angioplasty: a balloon was inserted at the site of the atherosclerotic lesion and then inflated to open the narrowed coronary artery. $2.5 \times 18 \mathrm{~mm}$ and $3.5 \times 18 \mathrm{~mm}$ balloons were used for Cases 1 and 2 , respectively.

2) Provisional side branch stenting technique (PSB): first, a stent in its crimped state was positioned in the main branch at the narrowing. Second, the stent was expanded by balloon inflation. Last, the balloon was deflated and the stent remained in place, holding the artery open. 2.5x18 mm Xience Prime and 3.5x18 mm Nobori stents were implanted in Cases 1 and 2, respectively.

Stent expansions were conducted in Abaqus/Explicit (Dassault Systèmes Simulia Corp., Providence, RI, USA) as a quasi-static process as discussed in detail elsewhere (Morlacchi et al., 2013, 2011).

To investigate the biomechanical influence of different stent designs and position, additional scenarios were also examined. Cases 1 and 2 were used to evaluate hemodynamic performance by comparing CFD results from Xience Prime and the Nobori stents. Case 2 was also used to evaluate 
the importance of stent positioning on the post-operative geometry obtained after virtual stent deployment relative to that from post-stent patient images via Hybrid $O C$-CT. Specifically, the Nobori stent was virtually implanted in three different positions by moving the stent distally relative to the first diagonal branch.

\subsection{CFD simulations}

Lumen and arterial wall deformations from FEA were extracted for CFD. Briefly, a NASTRAN file exported from ICEM CFD was loaded into ParaView (Kitware Inc., Clifton Park, NY, USA) where the surface was extracted and saved as a VTK multiblock file. A discrete solid model was then created from this surface file using SimVascular. Faces were renamed to delineate between those of the stent and artery wall for use in assigning edge sizes to mesh elements. Meshing parameters were iteratively adjusted until the meshing procedure was successful at writing out a mesh of sufficient density to resolve local flow features, while working within the computational limits of the local CPU (HP Z420 E5-1620 3.6 GHz workstations with 16GB RAM). Meshing parameters included a default global max edge size of $1.0 \mathrm{~mm}, 0.15 \mathrm{~mm}$ edge size for wall faces, and $0.04 \mathrm{~mm}$ edge size for stent faces. The wall and stent face minimum edge sizes were then adjusted on a case-by-case basis until a successful mesh was achieved. Any meshing errors could typically be mitigated for faces on the wall by reducing the size of elements to 0.1-0.08 mm. Errors on stent faces could similarly be mitigated by reducing local edges sizes to $0.02-0.008 \mathrm{~mm}$.

Boundary conditions for CFD were determined from patient-specific anthropometric data as discussed elsewhere (Ellwein et al., 2011). Briefly, using cardiac output, blood flow through the artery undergoing stenting was determined assuming the coronary arteries receive $5 \%$ of the cardiac output, and the right and left coronary arteries receive $16 \%$ and $84 \%$, respectively (Ellwein et al., 2011; Leaman et al., 1981). A typical coronary inflow waveform (Fig. 4) (LaDisa Jr. et al., 2002) was then scaled to match the mean blood flow, and introduced as a time-varying Womersley velocity profile. Blood was assumed to be a Newtonian fluid with a viscosity and constant density of $4 \mathrm{cP}$ and $1,060 \mathrm{~kg} / \mathrm{m}^{3}$, respectively. WSS was assumed to be equal in the main vessel and side branches (Ellwein et al., 2011; Williams et al., 2010). A three-element Windkessel representation was applied at each outlet (Table 3) to replicate the physiological influence of the arterial tree distal to the arteries in the computational model after stent implantation (Ellwein et al., 2011; Williams et al., 2010).

CFD simulations were run using an in house stabilized finite element solver with commercial linear solver component LESLIB (Altair Engineering) to solve the time-dependent Navier-Stokes 
equations. Standard convergence criteria were employed and simulations were run until the outlet pressure and flow were periodic.

\subsection{Analysis of results}

The open-source software PyFormex (www.nongnu.org/pyformex/) was used to quantify the distance between lumen surfaces of the post-stent geometry obtained after virtual stent deployment and Hybrid $O C$-CT. The two geometries were manually registered using the position of the side branches as a reference. The area of the geometry obtained after virtual stent deployment with a distance greater than $0.25 \mathrm{~mm}$ (i.e. twice the strut thickness of the Nobori stent) was then calculated.

Malapposed struts (defined as struts not in contact or within $0.1 \mathrm{~mm}$ of the lumen surface) were identified (Iannaccone et al., 2014). The percent area of malapposed struts with respect to the total area of the abluminal stent surface was calculated. Although the relation between incomplete stent apposition and adverse cardiovascular events is still under debate, it has been shown that malapposed struts can alter shear stress distribution, potentially leading to stent thrombosis (Attizzani et al., 2014).

Indices of WSS previously linked to NT were also determined. Time-averaged WSS (TAWSS) and oscillatory shear index (OSI) were computed over the last cardiac cycle as in previous studies (He and Ku, 1996; Tang et al., 2006) and visualized using ParaView. It has been shown that low TAWSS $(<0.4 \mathrm{~Pa})$ and high temporal oscillations quantified by OSI $(>0.1)$ are associated with NT (LaDisa Jr. et al., 2005; Malek et al., 1999; Wentzel et al., 2008), therefore the artery surface exposed to values outside these limits was used to quantify the impact of the implanted stent.

\section{RESULTS}

The reliability of FEA for virtual stent deployment was first verified. FEA took $\sim 24$ hours on one node of a cluster (two quad-core Intel Xeon E5620 $2.40 \mathrm{GHz}$ with $3 \mathrm{~GB}$ RAM and INFINIBAND Mellanox interconnections). Figure 5 shows superimposition of the post-operative lumen geometry obtained after virtual stent expansion and that from Hybrid OC-CT. A good qualitative agreement between the two geometries can be observed for both cases. Regions of the post-operative geometries obtained after virtual stent expansion with a distance $>0.25 \mathrm{~mm}$ relative to those reconstructed from Hybrid $O C-C T$ are highlighted in red. Percent differences in area were $14.8 \%$ and $20.4 \%$ for Cases 1 and 2, respectively.

Malapposed struts are highlighted in red in Figs.6-7 for both cases, and the percent area of malapposed struts is reported in Table 4 for both Xience Prime and Nobori stents. For Case 1, 
malapposed struts are only present in the bifurcation ostium (Fig.6). For Case 2, malapposed struts are localized at the bifurcation ostia and also at the proximal part of the stent (Fig.7). The percent area of malapposed struts was reduced from $\sim 4.9 \%$ to $\sim 1.3 \%$ by moving the Nobori stent distally to the first branch from Position A to Position C (Table 4, Fig.7). The Xience Prime showed a lower percentage of malapposition than Nobori implanted in the implanted position (i.e. Position B), likely due to its different stent design impacting interaction with components of the arterial wall.

CFD analysis was subsequently performed to quantify post-stenting results between different stent designs. After optimizing the local mesh edge size for 2-6 hours depending on the model being studied, CFD run times averaged $\sim 15$ hours per simulation (range 8-26 hours) using 56 cores of an Intel Nehalem cluster with $3 \mathrm{~GB} /$ core of RAM.

Distributions of TAWSS for Case 1 are shown in Fig.8. The patient for this case was implanted with a $2.5 \times 18 \mathrm{~mm}$ Xience Prime stent (Fig.8A). Virtual implantation of a 2.5x18 mm Nobori stent is also shown for comparison (Fig.8B). Portions of the artery lumen exposed to adverse TAWSS previously implicated in NT (i.e. $<0.4 \mathrm{~Pa}$ ) are also shown in the figure. The area of low TAWSS was more pronounced for the Nobori stent as compared to the Xience Prime stent that was actually implanted (6.80\% vs $4.07 \%$, Table 5). Straightening of the artery caused skewing of the velocity profile toward the surface nearest the bifurcation, and resulted in a pronounced area of low TAWSS on the opposite surface within the proximal portion of the stent. A second focal region of low TAWSS was found directly opposite the bifurcation. The degree to which this region extended circumferentially was influenced by the stent implanted, and the orientation of struts within this region. Sites of low TAWSS were more pronounced around struts of the Nobori stent due to their greater thickness. This prevented re-establishing of local near-wall velocity patterns as was observed distal to the bifurcation for the Xience Prime stent. Distributions of OSI are shown in Fig.9. Overall artery morphology in the proximal stented region and the bifurcation also contributed to elevated OSI in these regions, but differences in the area exposed to OSI $>0.1$ were more modest than for TAWSS $(3.55 \%$ vs $3.70 \%$ for the Xience Prime and Nobori stents, respectively, Table 5).

Distributions of TAWSS for Case 2 are shown in Fig.10. The patient for this case was implanted with a $3.5 \times 18 \mathrm{~mm}$ Nobori stent (Fig.10A) and virtual implantation of a 3.5x18 mm Xience Prime stent is also shown for comparison (Fig.10B). Areas of low TAWSS were localized to the entrance region of both stents where there was a sudden expansion in diameter, as well as downstream from an adjacent region of residual plaque and malapposition in the Nobori stent. The area of low TAWSS in Case 2 was also more pronounced for the Nobori stent as compared to the Xience Prime stent (27.1\% vs $22.5 \%$, Table 5). The regions of sudden expansion and downstream of the residual plaque within the stent also contributed to elevated OSI in these regions (Fig.11), and differences in 
the area exposed to OSI $>0.1$ were more pronounced than for Case $1(8.15 \%$ vs $6.02 \%$ for the Nobori and Xience Prime, respectively, Table 5).

\section{DISCUSSION}

The use of computer models for predicting and interpreting outcomes related to the treatment of coronary artery bifurcation stenting is gaining popularity, and garining an increasing level of interest (Migliavacca et al., 2015; Mortier et al., 2015, 2010). This is likely due in large part to a number of papers in recent years showing how patient-specific data can be used to precisely reproduce the anatomy of a coronary bifurcation, which can then be subjected to virtual bench testing of stents. These computational studies have generated striking agreement with experimental results suggesting they can be useful and powerful tools that shed additional light on aspects of interest to interventional cardiologists (Chiastra et al., 2015). This approach is particularly useful for the quantification of stent malapposition or indices of WSS in stented regions that are not immediately measurable during a procedure. With this in mind, the current investigation underscores the use of patient-specific FEA with subsequent CFD modeling as a means of predicting post-operative scenarios without necessarily having to physical deploy a stent. The main findings of this work are related to verifying FEA of stent expansion, successful integration of a workflow combining multiple software packages for solid and fluid mechanics analysis, and an alignment of patient-specific CFD results generated from this workflow with stent design features that have been shown to be important in idealized studies to date.

In completing the objective above, the current work acheives several notable 'firsts'. In contrast to using an idealized artery or single imaging modality for reconstruction before FEA, the pre-PCI and post-stenting artery geometries here were created using Hybrid $O C$-CT, which allows for reconstruction at $15 \mu \mathrm{m}$ resolution. The pre-PCI reconstruction was used as the starting point for FEA, and the post-stenting reconstruction was used to scrutinize the accuracy of its subsequent local deformations, which represents another unique aspect of the current investigation. The use of a sequential approach (i.e. from FEA to CFD analyses) allowed us to take also into account the local deformation of the artery lumen due to stent expansion. As previously demonstrated (Martin et al., 2014; Morlacchi et al., 2011), local hemodynamics are very sensitive to the stented geometry and a sequential approach can provide a more accurate replication of the local hemodynamic environment.

The arterial geometries obtained after virtual expansion were qualitatevely in good agreement with those from patient images. Quantitative comparison between the post-stent geometries resulted in a maximum difference in area of $20.4 \%$ (Case 2). We believe this is a very promising result. The 
manual registration process followed in this study is believed to have resulted in overestimation of differences in geometry obtained after virtual stent deployment relative to the geometry reconstructed from patient images. An optimization process could be implented for registration of the post-stent geometries in order to minimize the areas with distance higher than $0.25 \mathrm{~mm}$.

We also presented a workflow that, while accounting for all the steps conducted by an interventional cardiologist, can systematically be used to quantify the relative contributions of geometrical factors (e.g. strut malapposition) and biomechanical stimuli. The consideration of factors from a solid mechanics (e.g. local deformation) and fluid mechanics (e.g. WSS) perspective is unique, but also very important since both have been implicated in restenosis and markers of late stent thrombosis. The approach presented here blends some of the most common and well documented software packages from both the commercial and open source domains. Although atypical, this approach allows us to leveage the best features from mutiple software packages and provides a starting point for other researcher to do the same.

The current work also paves the way for the use of simulations in larger trials to predictively evaluate the optimal stent for a given patient and/or assess their risk for suboptimal clinical outcomes rooted in biomechanics after coronary artery DES implantation. For example, the notion of being able to select the optimal stent for a given patient was investigated for both cases by comparing the Xience Prime and Nobori stents in terms of malapposition, TAWSS, and OSI results. The best stent position was evaluted virtually by implanting the Nobori stent in three different positions. The percentage of malapposed struts was reduced by moving the stent distally to the first branch. The case with the stent in its implanted position (Position B) showed results bounded by the two extreme positions. The patient-specific cases presented here also confirm conclusions from prior idealized studies regarding stent design characteristics and their effect on adverse WSS distributions. Stent geometry has been shown to affect the distribution of WSS, and, in turn, affect NT (LaDisa Jr. et al., 2005). Gundert et al. (Gundert et al., 2013) reviewed a hierarchy of factors that can result in adverse WSS distributions by virtually implanting various stents into idealized coronary arteries. The hierarchy includes strut thickness that was drastically different between the two stents used in the current investigation, stent-to-lumen area ratio, angle of struts relative to the primary direction of blood flow, and the arrangement of connector elements (Gundert et al., 2012). However, it is concevible that not all patient-specific CFD simulations conduted from FEA will adhere to this hierarchy of design features elucidated by theoretical stented CFD models. Exclusions may include stents with similar strut thicknesses, or patients with a more complex plaque distribution creating a heterogeneity in material properties within the stented region. 
The advancements shown in this work are perfectly timed as $~ 150$ key opinion leaders from academia, industry and cardiology recently expressed their willingness to adopt a new way of thinking that includes the possibility of simulating interventions using patient-specific data (Stankovic et al., 2013). Unfortunately enthusiasm is tempered by the fact that translation of virtual patient-specific computational modeling to the clinic is dependent on the time needed to obtain the results, as well as to their reliability. To complete the full procedure applied here (artery reconstruction and its discretization, setting of FEA and CFD models, and solving, excluding the time for image acquiring and creation of stent and balloon models), $\sim 3$ days are required with the available computational resources. Further advancements to speed up and automate the procedure are therefore required.

Although this study shows promising results, some limitations are present. The arterial wall thickness and the external wall geometry could not be deduced from available imaging data. The plaque identification process might be improved with more tissue testing and expedited by implementing a semi-automatic algorithm for delineating the location and composition of plaque from OCT data (Celi and Berti, 2014; Celi et al., 2013). Limitations of the CFD simulations are related to the boundary conditions imposed, use of a Newtonian fluid, and neglecting movement of the arterial wall after stent implantation. Closed-loop, lumped-parameter networks, initially developed to model single ventricle physiology, were recently applied to the coronary arteries (Sankaran et al., 2012). Implementation of these tools would better replicate relationships between local flow and global circulatory dynamics (Bove et al., 2007; Corsini et al., 2011; Kim et al., 2010). The rigid-wall assumption implemented here appears adequate when the aim of the study is the analysis of near-wall hemodynamic quantities (Chiastra et al., 2014) within the stent since implantation typically renders most of the artery rigid (LaDisa Jr. et al., 2002).

\section{CONCLUSIONS}

The methodology described here to virtually simulate stent implantation is reliable by taking into account intrinsic errors and assumptions due to image reconstruction and numerical modeling. Furthermore, the proposed workflow (from FEA to CFD analyses) may provide useful information for pre-interventional planning by choosing the optimal stent type and position for each individual's anatomy.

\section{ACKNOWLEDGEMENTS}

This work was supported in part by National Science Foundation (NSF) awards OCI-0923037 and CBET-0521602. Claudio Chiastra is partially supported by the ERC starting grant (310457, 
BioCCora). Wei Wu is supported by the Politecnico di Milano International Fellowship (PIF) 413 program. The authors acknowledge Laura Ellwein PhD (Assistant Professor of Mathematics at 414 Virginia Commonwealth University, Richmond, VA, USA) for implementation of the Hybrid OC$C T$ approach.

\section{CONFLICT OF INTEREST}

418 The authors have no conflicts of interest to declare.

\section{REFERENCES}

Attizzani, G.F., Capodanno, D., Ohno, Y., Tamburino, C., 2014. Mechanisms, pathophysiology, and clinical aspects of incomplete stent apposition. J. Am. Coll. Cardiol. 63, 1355-67.

Bove, E.L., de Leval, M.R., Migliavacca, F., Balossino, R., Dubini, G., 2007. Toward optimal hemodynamics: computer modeling of the Fontan circuit. Pediatr. Cardiol. 28, 477-81.

Capelli, C., Gervaso, F., Petrini, L., Dubini, G., Migliavacca, F., 2009. Assessment of tissue prolapse after balloon-expandable stenting: influence of stent cell geometry. Med. Eng. Phys. 31, 441-7.

Celi, S., Berti, S., 2014. In-vivo segmentation and quantification of coronary lesions by optical coherence tomography images for a lesion type definition and stenosis grading. Med. Image Anal. 18, 1157-1168.

Celi, S., Vaghetti, M., Palmieri, C., Berti, S., 2013. Superficial coronary calcium analysis by OCT: Looking forward an imaging algorithm for an automatic 3D quantification. Int. J. Cardiol. 168, 2958-2960.

Chiastra, C., Grundeken, M.J., Wu, W., Serruys, P.W., de Winter, R.J., Dubini, G., Wykrzykowska, J.J., Migliavacca, F., 2015. First report on free expansion simulations of a dedicated bifurcation stent mounted on a stepped balloon. EuroIntervention 10, e1-3.

Chiastra, C., Migliavacca, F., Martinez, M.A., Malve, M., 2014. On the necessity of modelling fluid-structure interaction for stented coronary arteries. J. Mech. Behav. Biomed. Mater. 34, 217-230.

Chiastra, C., Morlacchi, S., Gallo, D., Morbiducci, U., Cárdenes, R., Larrabide, I., Migliavacca, F., 2013. Computational fluid dynamic simulations of image-based stented coronary bifurcation models. J. R. Soc. Interface 10, 20130193.

Corsini, C., Cosentino, D., Pennati, G., Dubini, G., Hsia, T.Y., Migliavacca, F., 2011. Multiscale models of the hybrid palliation for hypoplastic left heart syndrome. J. Biomech. 44, 767-770.

Dangas, G.D., Claessen, B.E., Caixeta, A., Sanidas, E. a., Mintz, G.S., Mehran, R., 2010. In-stent restenosis in the drug-eluting stent era. J. Am. Coll. Cardiol. 56, 1897-1907. 
Ellwein, L.M., Otake, H., Gundert, T.J., Koo, B.-K., Shinke, T., Honda, Y., Shite, J., LaDisa, J.F., 2011. Optical Coherence Tomography for Patient-specific 3D Artery Reconstruction and Evaluation of Wall Shear Stress in a Left Circumflex Coronary Artery. Cardiovasc. Eng. Technol. 2, 212-227.

Farooq, M.U., Khasnis, A., Majid, A., Kassab, M.Y., 2009. The role of optical coherence tomography in vascular medicine. Vasc. Med. 14, 63-71.

Ferrante, G., Presbitero, P., Whitbourn, R., Barlis, P., 2013. Current applications of optical coherence tomography for coronary intervention. Int. J. Cardiol. 165, 7-16.

Foin, N., Gutiérrez-Chico, J.L., Nakatani, S., Torii, R., Bourantas, C. V., Sen, S., Nijjer, S., Petraco, R., Kousera, C., Ghione, M., Onuma, Y., Garcia-Garcia, H.M., Francis, D.P., Wong, P., Di Mario, C., Davies, J.E., Serruys, P.W., 2014. Incomplete stent apposition causes high shear flow disturbances and delay in neointimal coverage as a function of strut to wall detachment distance implications for the management of incomplete stent apposition. Circ. Cardiovasc. Interv. 7, 180-189.

Gundert, T.J., Dholakia, R.J., McMahon, D., LaDisa, J.F., 2013. Computational fluid dynamics evaluation of equivalency in hemodynamic alterations between Driver, Integrity, and similar stents implanted into an idealized coronary artery. J. Med. Device. 7, 11004.

Gundert, T.J., Marsden, A.L., Yang, W., Marks, D.S., LaDisa Jr., J.F., 2012. Identification of hemodynamically optimal coronary stent designs based on vessel caliber. IEEE Trans Biomed Eng 59, 1992-2002.

Gundert, T.J., Shadden, S.C., Williams, A.R., Koo, B.K., Feinstein, J. a., Ladisa, J.F., 2011. A rapid and computationally inexpensive method to virtually implant current and next-generation stents into subject-specific computational fluid dynamics models. Ann. Biomed. Eng. 39, $1423-1437$.

He, X., Ku, D.N., 1996. Pulsatile flow in the human left coronary artery bifurcation: average conditions. J. Biomech. Eng 118.

Holzapfel, G.A., Sommer, G., Gasser, C.T., Regitnig, P., 2005. Determination of layer-specific mechanical properties of human coronary arteries with nonatherosclerotic intimal thickening and related constitutive modeling. Am J Physiol Hear. Circ Physiol 289, H2048-58.

Iannaccone, F., De Bock, S., De Beule, M., Vermassen, F., Van Herzeele, I., Verdonck, P., Segers, P., Verhegghe, B., 2014. Feasibility of a priori numerical assessment of plaque scaffolding after carotid artery stenting in clinical routine: proof of concept. Int. J. Artif. Organs 37, 928939.

Katritsis, G.D., Siontis, G.C.M., Ioannidis, J.P. a, 2009. Double versus single stenting for coronary bifurcation lesions a meta-analysis. Circ. Cardiovasc. Interv. 2, 409-415.

Kim, H.J., Vignon-Clementel, I.E., Figueroa, C. a., Jansen, K.E., Taylor, C. a., 2010. Developing computational methods for three-dimensional finite element simulations of coronary blood flow. Finite Elem. Anal. Des. 46, 514-525. 
Kornowski, R., Hong, M.K., Tio, F.O., Bramwell, O., Wu, H., Leon, M.B., 1998. In-stent restenosis: Contributions of inflammatory responses and arterial injury to neointimal hyperplasia. J. Am. Coll. Cardiol. 31, 224-230.

LaDisa Jr., J.F., Hettrick, D.A., Olson, L.E., Guler, I., Gross, E.R., Kress, T.T., Kersten, J.R., Warltier, D.C., Pagel, P.S., 2002. Stent implantation alters coronary artery hemodynamics and wall shear stress during maximal vasodilation. J Appl Physiol 93, 1939-1946.

LaDisa Jr., J.F., Olson, L.E., Molthen, R.C., Hettrick, D.A., Pratt, P.F., Hardel, M.D., Kersten, J.R., Warltier, D.C., Pagel, P.S., 2005. Alterations in wall shear stress predict sites of neointimal hyperplasia after stent implantation in rabbit iliac arteries. Am J Physiol Hear. Circ Physiol 288, H2465-75.

Lassen, J.F., Holm, N.R., Stankovic, G., Lefèvre, T., Chieffo, A., Hildick-Smith, D., Pan, M., Darremont, O., Albiero, R., Ferenc, M., Louvard, Y., 2014. Percutaneous coronary intervention for coronary bifurcation disease: consensus from the first 10 years of the European Bifurcation Club meetings. EuroIntervention 10, 545-60.

Leaman, D.M., Brower, R.W., Meester, G.T., Serruys, P., van den Brand, M., 1981. Coronary artery atherosclerosis: severity of the disease, severity of angina pectoris and compromised left ventricular function. Circulation 63, 285-299.

Lemos, P.A., Serruys, P.W., van Domburg, R.T., Saia, F., Arampatzis, C.A., Hoye, A., Degertekin, M., Tanabe, K., Daemen, J., Liu, T.K.K., McFadden, E., Sianos, G., Hofma, S.H., Smits, P.C., van der Giessen, W.J., de Feyter, P.J., 2004. Unrestricted utilization of sirolimus-eluting stents compared with conventional bare stent implantation in the "real world": the RapamycinEluting Stent Evaluated At Rotterdam Cardiology Hospital (RESEARCH) registry. Circulation 109, 190-5.

Loree, H.M., Grodzinsky, A.J., Park, S.Y., Gibson, L.J., Lee, R.T., 1994. Static circumferential tangential modulus of human atherosclerotic tissue. J Biomech 27, 195-204.

Malek, a M., Alper, S.L., Izumo, S., 1999. Hemodynamic shear stress and its role in atherosclerosis. JAMA 282, 2035-2042.

Martin, D.M., Murphy, E. a., Boyle, F.J., 2014. Computational fluid dynamics analysis of balloonexpandable coronary stents: Influence of stent and vessel deformation. Med. Eng. Phys. 36, 1047-1056.

Mauri, L., Silbaugh, T.S., Wolf, R.E., Zelevinsky, K., Lovett, A., Zhou, Z., Resnic, F.S., Normand, S.-L.T., 2008. Long-term clinical outcomes after drug-eluting and bare-metal stenting in Massachusetts. Circulation 118, 1817-27.

Migliavacca, F., Chiastra, C., Chatzizisis, Y.S., Dubini, G., 2015. Virtual bench testing to study coronary bifurcation stenting. EuroIntervention 11 Suppl V, V31-V34.

Morlacchi, S., Chiastra, C., Gastaldi, D., Giancarlo, P., Dubini, G., Migliavacca, F., 2011. Sequential structural and fluid Dynamic numerical simulations of a stented bifurcated coronary artery. J. Biomech. Eng. 133, 121010. 
Morlacchi, S., Colleoni, S.G., Cárdenes, R., Chiastra, C., Diez, J.L., Larrabide, I., Migliavacca, F., 2013. Patient-specific simulations of stenting procedures in coronary bifurcations: two clinical cases. Med. Eng. Phys. 35, 1272-81.

Mortier, P., De Beule, M., Dubini, G., Hikichi, Y., Murasato, Y., Ormiston, J.A., 2010. Coronary bifurcation stenting: insights from in vitro and virtual bench testing. EuroIntervention 6 Suppl J, J53-60.

Mortier, P., De Beule, M., Segers, P., Verdonck, P., Verhegghe, B., 2011. Virtual bench testing of new generation coronary stents. EuroIntervention 7, 369-376.

Mortier, P., Wentzel, J.J., De Santis, G., Chiastra, C., Migliavacca, F., De Beule, M., Louvard, Y., Dubini, G., 2015. Patient-specific computer modelling of coronary bifurcation stenting: the John Doe programme. EuroIntervention 11 Suppl V, V35-V39.

Morton, A.C., Crossman, D., Gunn, J., 2004. The influence of physical stent parameters upon restenosis. Pathol. Biol. 52, 196-205.

Nakazato, R., Otake, H., Konishi, A., Iwasaki, M., Koo, B.-K., Fukuya, H., Shinke, T., Hirata, K.-I., Leipsic, J., Berman, D.S., Min, J.K., 2015. Atherosclerotic plaque characterization by CT angiography for identification of high-risk coronary artery lesions: a comparison to optical coherence tomography. Eur. Heart J. Cardiovasc. Imaging 16, 373-9.

Otake, H., Shite, J., Ako, J., Shinke, T., Tanino, Y., Ogasawara, D., Sawada, T., Miyoshi, N., Kato, H., Koo, B.K., Honda, Y., Fitzgerald, P.J., Hirata, K., 2009. Local determinants of thrombus formation following sirolimus-eluting stent implantation assessed by optical coherence tomography. JACC Cardiovasc Interv 2, 459-466.

Sankaran, S., Esmaily Moghadam, M., Kahn, A.M., Tseng, E.E., Guccione, J.M., Marsden, A.L., 2012. Patient-specific multiscale modeling of blood flow for coronary artery bypass graft surgery. Ann Biomed Eng 40, 2228-2242.

Schwartz, R.S., Huber, K.C., Murphy, J.G., Edwards, W.D., Camrud, a R., Vlietstra, R.E., Holmes, D.R., 1992. Restenosis and the proportional neointimal response to coronary artery injury: results in a porcine model. J. Am. Coll. Cardiol. 19, 267-274.

Stankovic, G., Lefevre, T., Chieffo, A., Hildick-Smith, D., Lassen, J.F., Pan, M., Darremont, O., Albiero, R., Ferenc, M., Finet, G., Adriaenssens, T., Koo, B.K., Burzotta, F., Louvard, Y., 2013. Consensus from the 7th European Bifurcation Club meeting. EuroIntervention 9, 36-45.

Tang, B.T., Cheng, C.P., Draney, M.T., Wilson, N.M., Tsao, P.S., Herfkens, R.J., Taylor, C.A., 2006. Abdominal aortic hemodynamics in young healthy adults at rest and during lower limb exercise: quantification using image-based computer modeling. Am J Physiol Hear. Circ Physiol 291, H668-76.

Timmins, L.H., Meyer, C. a, Moreno, M.R., Moore, J.E., 2008. Effects of stent design and atherosclerotic plaque composition on arterial wall biomechanics. J. Endovasc. Ther. 15, 643654.

Timmins, L.H., Miller, M.W., Clubb, F.J., Moore, J.E., 2011. Increased artery wall stress poststenting leads to greater intimal thickening. Lab. Invest. 91, 955-967. 
Waksman, R., Kitabata, H., Prati, F., Albertucci, M., Mintz, G.S., 2013. Intravascular ultrasound versus optical coherence tomography guidance. J. Am. Coll. Cardiol. 62, S32-S40.

Wentzel, J.J., Gijsen, F.J.H., Schuurbiers, J.C.H., van der Steen, A.F.W., Serruys, P.W., 2008. The influence of shear stress on in-stent restenosis and thrombosis. EuroIntervention 4 Suppl C, C27-C32.

Williams, A.R., Koo, B.-K., Gundert, T.J., Fitzgerald, P.J., LaDisa, J.F., 2010. Local hemodynamic changes caused by main branch stent implantation and subsequent virtual side branch balloon angioplasty in a representative coronary bifurcation. J. Appl. Physiol. 109, 532-40.

Zahn, R., Hamm, C.W., Schneider, S., Zeymer, U., Nienaber, C.A., Richardt, G., Kelm, M., Levenson, B., Bonzel, T., Tebbe, U., Sabin, G., Senges, J., 2005. Incidence and predictors of target vessel revascularization and clinical event rates of the sirolimus-eluting coronary stent (results from the prospective multicenter German Cypher Stent Registry). Am. J. Cardiol. 95, 1302-8.

Zhang, F., Dong, L., Ge, J., 2009. Simple versus complex stenting strategy for coronary artery bifurcation lesions in the drug-eluting stent era: a meta-analysis of randomised trials. Heart 95, 1676-81. 


\section{TABLE CAPTIONS}

580

581 Table 1 - Coefficients of strain energy density function for the arterial wall and the atherosclerotic 582 plaques.

583

584 Table 2 - Geometric characteristics of the stent models

585

586 Table 3 - Parameters of the three-element Windkessel model applied at each outlet for the two 587 cases studied.

588

589

590

591 Table 5 - Indices of wall shear stress (WSS) including time-averaged wall shear stress (TAWSS)

592 and oscillatory shear index (OSI). These indices were compared between the implanted stent for

593 Cases 1 and 2 (Xience Prime and Nobori, respectively) and virtual implantation of the second stent. 


\section{FIGURE CAPTIONS}

Figure 1 - Creation of a patient-specific coronary artery bifurcation model using Case 1 as an example. A) Hybrid OC-CT method to obtain the 3D lumen geometry (Ellwein et al., 2011): (top) detection of lumen contours, (center) registration of the detected contours orthogonal to the imaging wire pathway, (bottom) final 3D lumen geometry, which was obtained by lofting lumen contours after registration. The center panel also shows differences between the imaging wire pathway (black) and the lumen centerline (grey). B) 3D solid model of the lumen and vessel wall.

Figure 2 - Plaque modeling. A) Plaque identification process (Morlacchi et al., 2013) using Case 2 as an example. The distance between each grid node and the centerline of the external wall is computed. The elements are characterized by assuming a distance less than the physiological lumen radius represents regions of plaque. B-C) Assignment of plaque composition, which is based on the information given by optical coherence tomography (OCT) images, for Cases 1 and 2, respectively.

Figure 3 - Main steps of the stenting procedure that was followed for Cases 1 (left) and 2 (right): A) insertion of the angioplasty balloon; B) expansion of the angioplasty balloon; C) insertion of the stent crimped on a balloon; D) stent expansion; E) final geometric configuration after stent recoil.

Figure 4 - Coronary waveforms used as inlet boundary conditions for CFD simulations. The mean inflow for each case was estimated from patient-specific anthropometric data assuming a normal cardiac index, that the coronary arteries receive 5\% of the cardiac output, and that the right and left coronary arteries receive $16 \%$ and $84 \%$, respectively. The coronary inflow waveform in the figure was then scaled to match the calculated mean blood flow, and introduced as a time-varying Womersley velocity profile.

Figure 5 - Comparison between the post-stenting geometry reconstructed from patient images (grey) and the geometry obtained after virtual stent deployment (blue) for Cases 1 (left) and 2 (right). Regions of the geometry obtained after virtual stent deployment that are greater than 0.25 $\mathrm{mm}$ from the geometry reconstructed from patient images are shown in red. Comparison was only performed in the stented region. Two views are shown for clarity as indicated by differences in the flow direction in the top vs bottom images. 
Figure 6 - Quantification of stent malapposition for Case 1: A) Xience Prime stent; B) Nobori stent. Malapposed struts are shown in red.

Figure 7 - Quantification of stent malapposition for Case 2. A-C) Nobori stent in the three positions investigated; D) Xience Prime stent. Malapposed struts are shown in red.

Figure 8 - Time-averaged wall shear stress (TAWSS) distributions for Case 1. Differences in TAWSS previously linked to neointimal thickness are shown in the figure and quantified in Table 5 by comparing CFD results from the implanted Xience Prime stent (A) vs the virtually-implanted Nobori stent (B). Two views are shown for clarity as indicated by differences in the flow direction in the left vs right images. The full range of TAWSS values is shown for both stents in each view. The lumen area exposed to the TAWSS $<0.4 \mathrm{~Pa}$ (see legend) is also isolated for both stents in each view.

Figure 9 - Oscillatory shear index (OSI) distributions for Case 1. Differences in OSI are shown in the figure and quantified in Table 5 by comparing CFD results from the implanted Xience Prime stent (A) vs the virtually-implanted Nobori stent (B). Two views are shown for clarity as indicated by differences in the flow direction in the left vs right images.

Figure 10 - Time-Averaged Wall Shear Stress (TAWSS) distributions for Case 2. Differences in TAWSS previously linked to neointimal thickness are shown in the figure and quantified in Table 5 by comparing CFD results from the implanted Nobori stent (A) vs the virtually-implanted Xience Prime stent (B). Two views are shown for clarity as indicated by differences in the flow direction in the left vs right images. The full range of TAWSS values is shown for both stents in each view. The lumen area exposed to the TAWSS $<0.4 \mathrm{~Pa}$ (see legend) is also isolated for both stents in each view.

Figure 11 - Oscillatory Shear Index (OSI) distributions for Case 2. Differences in OSI are shown in the figure and quantified in Table 5 by comparing CFD results from the implanted Nobori stent (A) vs the virtually-implanted Xience Prime stent (B). Two views are shown for clarity as indicated by differences in the flow direction in the left vs right images. 
TABLES

665

Table 1 - Coefficients of strain energy density function for the arterial wall and the atherosclerotic plaques

\begin{tabular}{ccccccc}
\hline & C10 [MPa] & C20 [MPa] & C30 [MPa] & C40 [MPa] & C50 [MPa] & C60 [MPa] \\
\hline $\begin{array}{c}\text { Arterial wall } \\
\text { (media layer) }\end{array}$ & $6.52 \mathrm{E}-03$ & $4.90 \mathrm{E}-02$ & $9.26 \mathrm{E}-03$ & $7.60 \mathrm{E}-01$ & $-4.30 \mathrm{E}-01$ & $8.70 \mathrm{E}-02$ \\
\hline Soft plaque & $2.38 \mathrm{E}-03$ & $1.90 \mathrm{E}-01$ & $-3.90 \mathrm{E}-01$ & $3.37 \mathrm{E}+00$ & $-2.54 \mathrm{E}+00$ & $5.70 \mathrm{E}-01$ \\
\hline Stiff plaque & $1.21 \mathrm{E}-02$ & $1.54 \mathrm{E}+00$ & $2.19 \mathrm{E}+00$ & $2.14 \mathrm{E}+02$ & $-3.35 \mathrm{E}+03$ & $1.34 \mathrm{E}+05$ \\
\hline
\end{tabular}

668

669

670

671

\begin{tabular}{cccc}
\hline Stent model & $\begin{array}{c}\text { External diameter } \\
(\text { expanded } \\
\text { configuration) }[\mathrm{mm}]\end{array}$ & $\begin{array}{c}\text { Length } \\
{[\mathbf{m m}]}\end{array}$ & $\begin{array}{c}\text { Strut thickness } \\
{[\boldsymbol{\mu m}]}\end{array}$ \\
\hline Xience Prime & $\begin{array}{c}2.5(\text { Case } 1) \\
3.5(\text { Case } 2)\end{array}$ & 18 & 81 \\
\hline Nobori & $\begin{array}{c}2.5(\text { Case } 1) \\
3.5(\text { Case } 2)\end{array}$ & 18 & 125 \\
\hline
\end{tabular}

Table 2 - Geometric characteristics of the stent models

\section{External diameter}

672

673

674

675

676 
Table 4 - Malapposition for all investigated cases.

\begin{tabular}{ccc}
\hline Case & Stent & $\begin{array}{c}\text { Malapposition } \\
\text { [perc. area with } \\
\text { distance > 0.1 mm] }\end{array}$ \\
\hline 1 & Xience Prime (Implanted) & $0.90 \%$ \\
1 & Nobori & $1.53 \%$ \\
\hline 2 & Nobori (pos. A) & $4.92 \%$ \\
2 & Nobori (pos. B - Implanted) & $2.35 \%$ \\
2 & Nobori (pos. C) & $1.32 \%$ \\
\hline
\end{tabular}

681

682

683

684 Table 5 - Indices of wall shear stress (WSS) including time-averaged wall shear stress (TAWSS)

685 and oscillatory shear index (OSI). These indices were compared between the implanted stent for

686 Cases 1 and 2 (Xience Prime and Nobori, respectively) and virtual implantation of the second stent.

687

\begin{tabular}{cccc}
\hline Case & Stent & $\begin{array}{c}\text { TAWSS } \\
\text { [perc. area } \\
\text { TAWSS }<\mathbf{0 . 4} \text { Pa] }\end{array}$ & $\begin{array}{c}\text { OSI } \\
\text { [perc. area with } \\
\text { OSI }>\mathbf{0 . 1}]\end{array}$ \\
\hline 1 & Xience Prime (Implanted) & $4.07 \%$ & $3.55 \%$ \\
1 & Nobori & $6.80 \%$ & $3.70 \%$ \\
2 & Nobori (Implanted) & $27.1 \%$ & $8.15 \%$ \\
2 & Xience Prime & $22.5 \%$ & $6.02 \%$ \\
\hline
\end{tabular}


A)

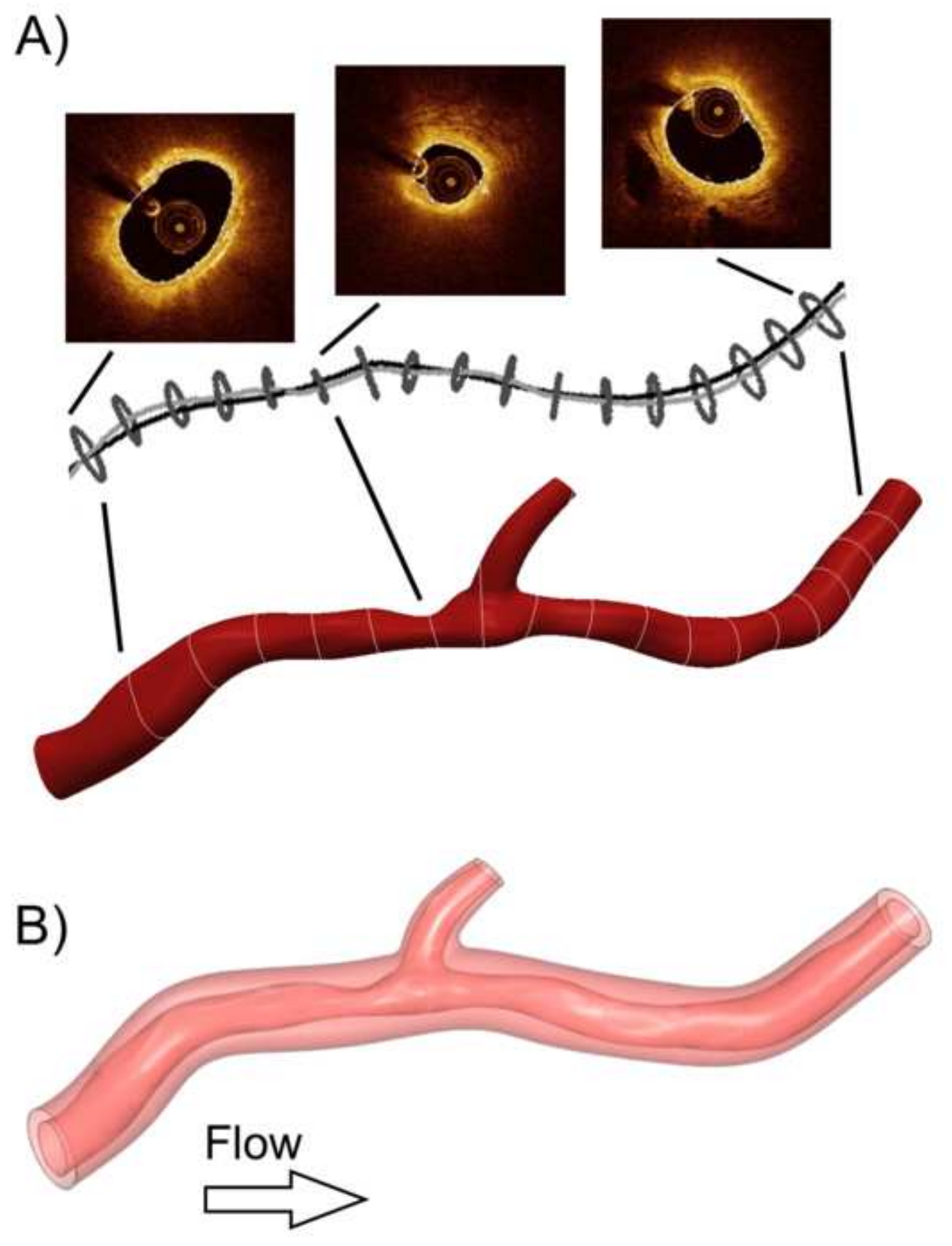

B)
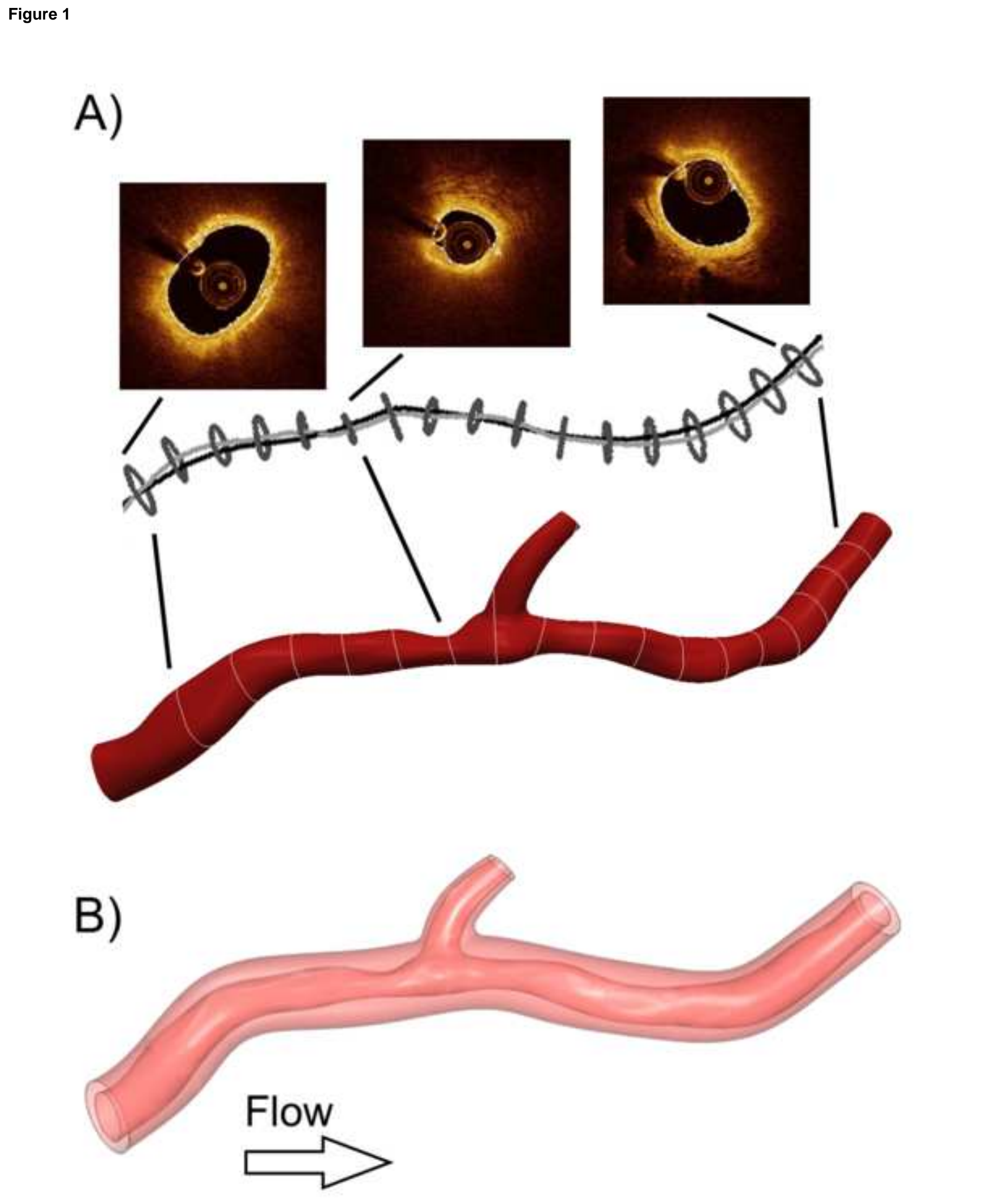

Figure 1

1
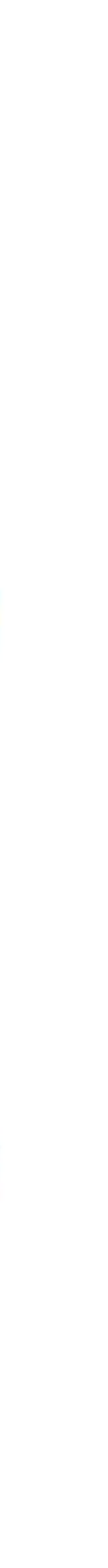

. 

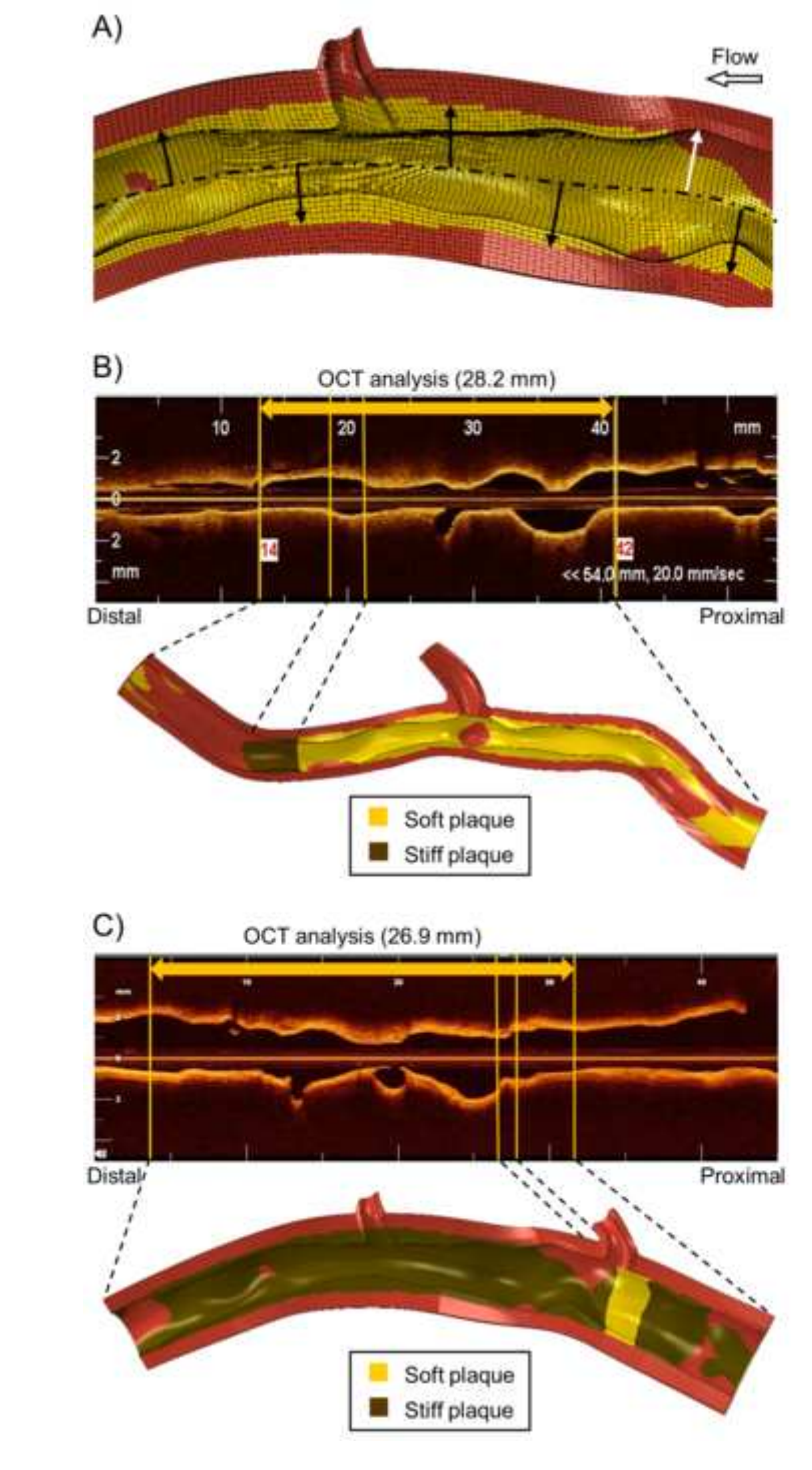

Figure 2

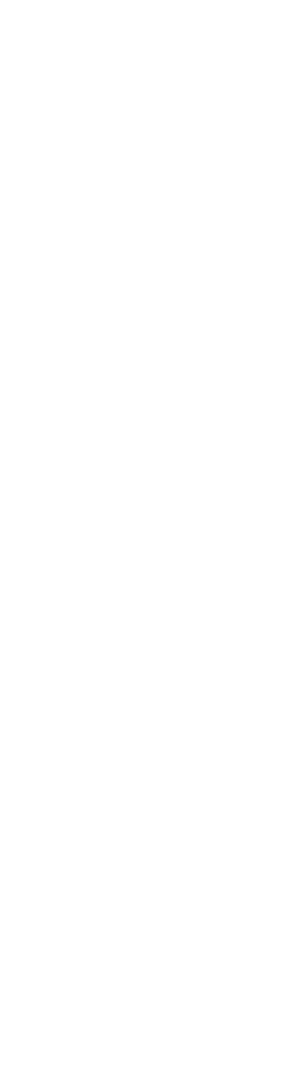

2

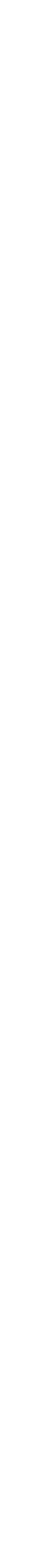

Figure 2
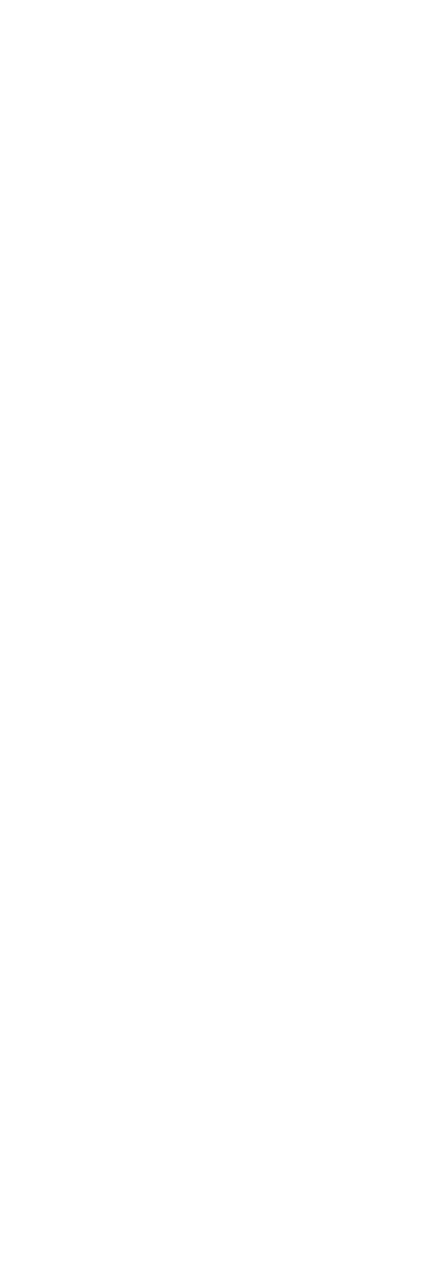
Case 1
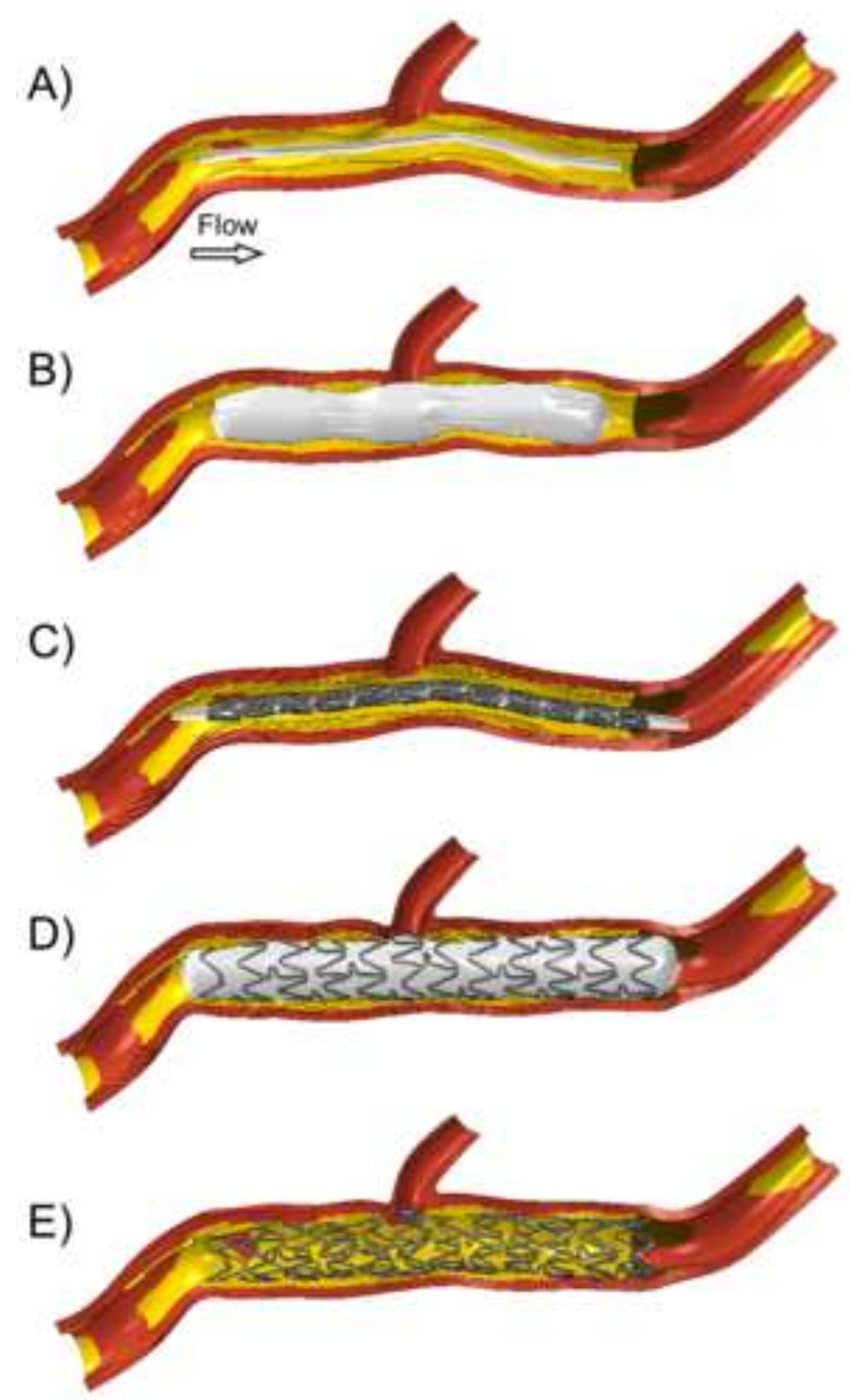

Case 2
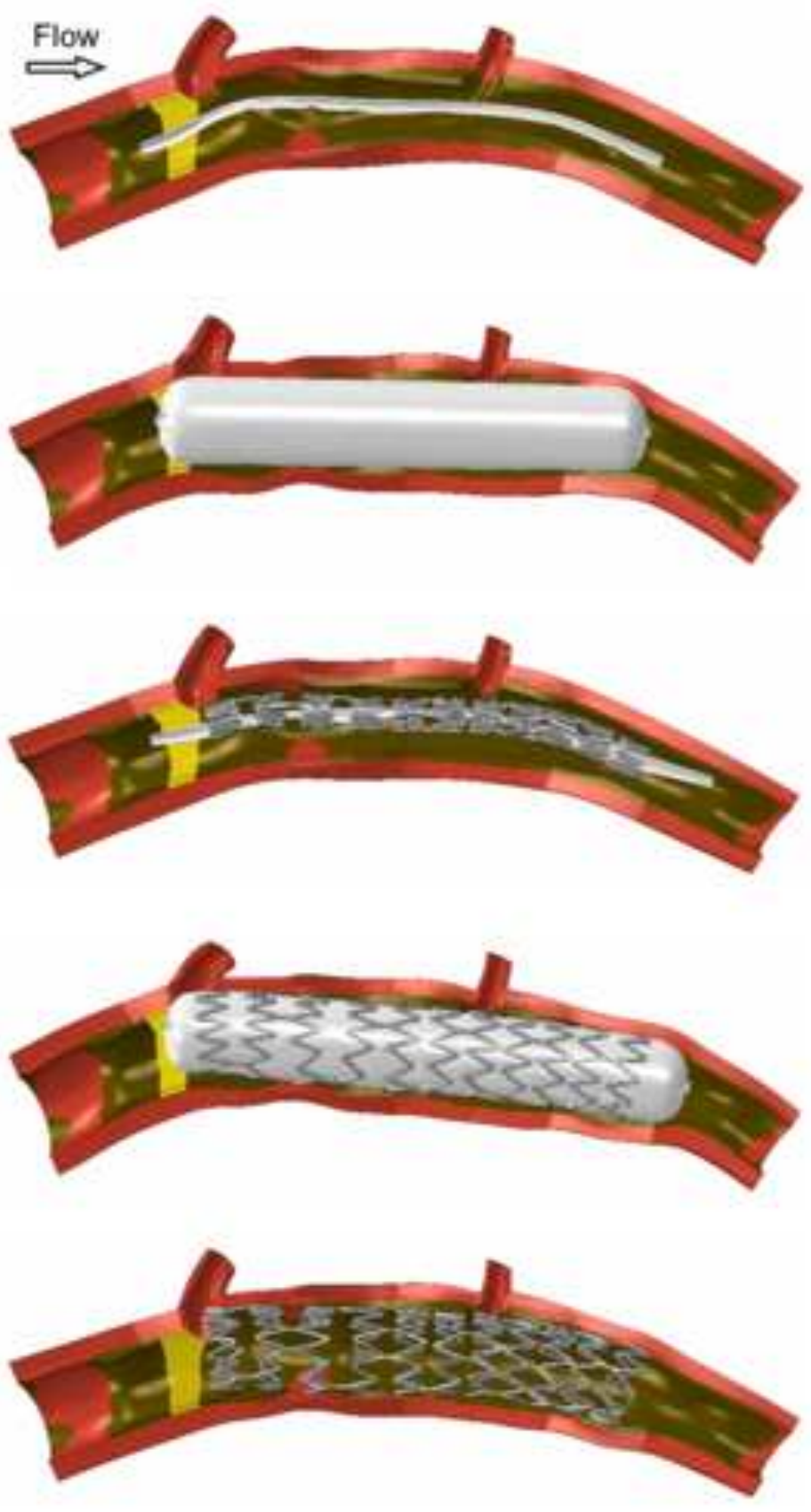


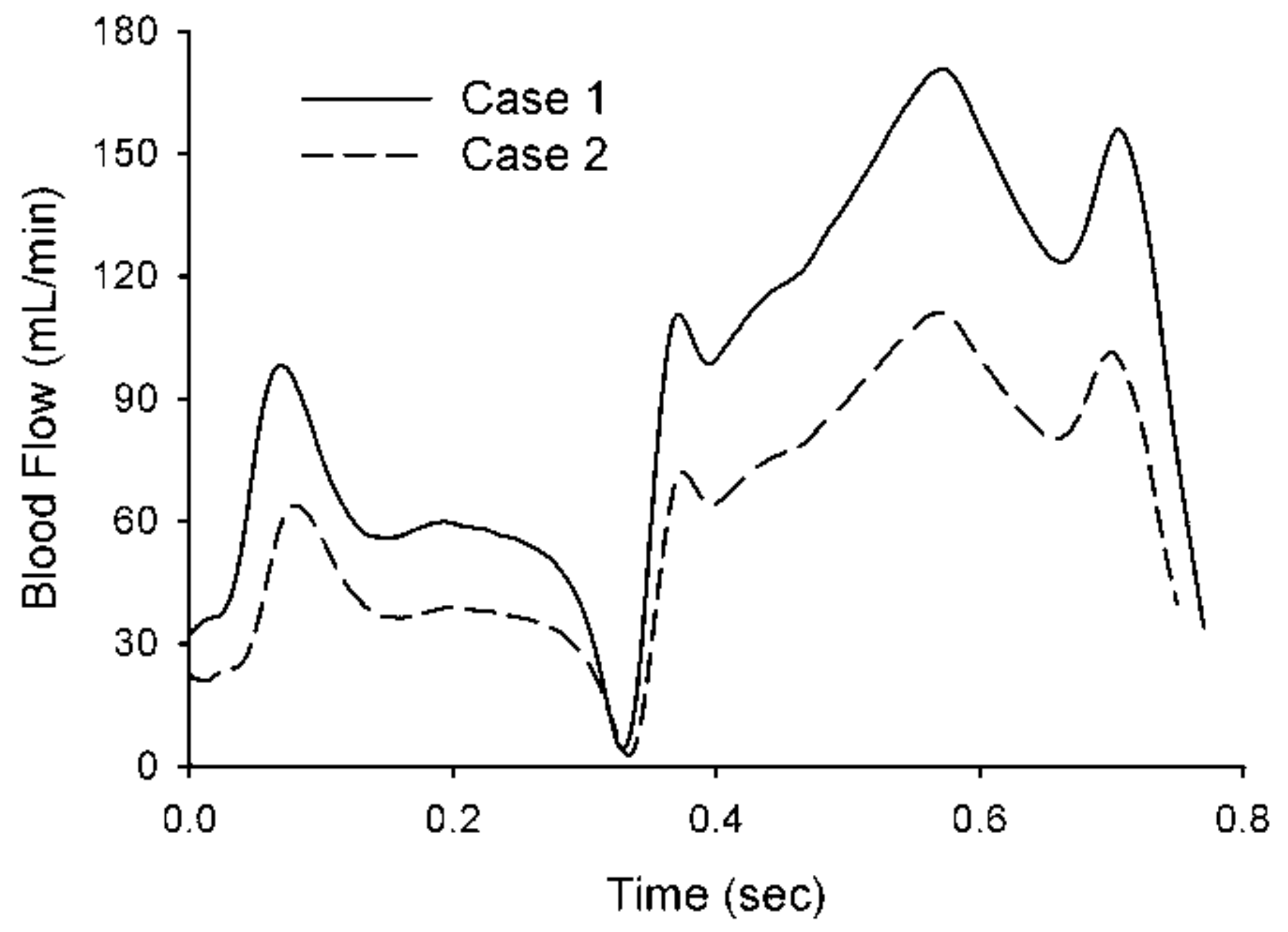


Case 1

\begin{tabular}{|l|}
\hline - From patient images \\
- Simulation \\
- Distance $>0.25 \mathrm{~mm}$ \\
\hline
\end{tabular}

Case 2
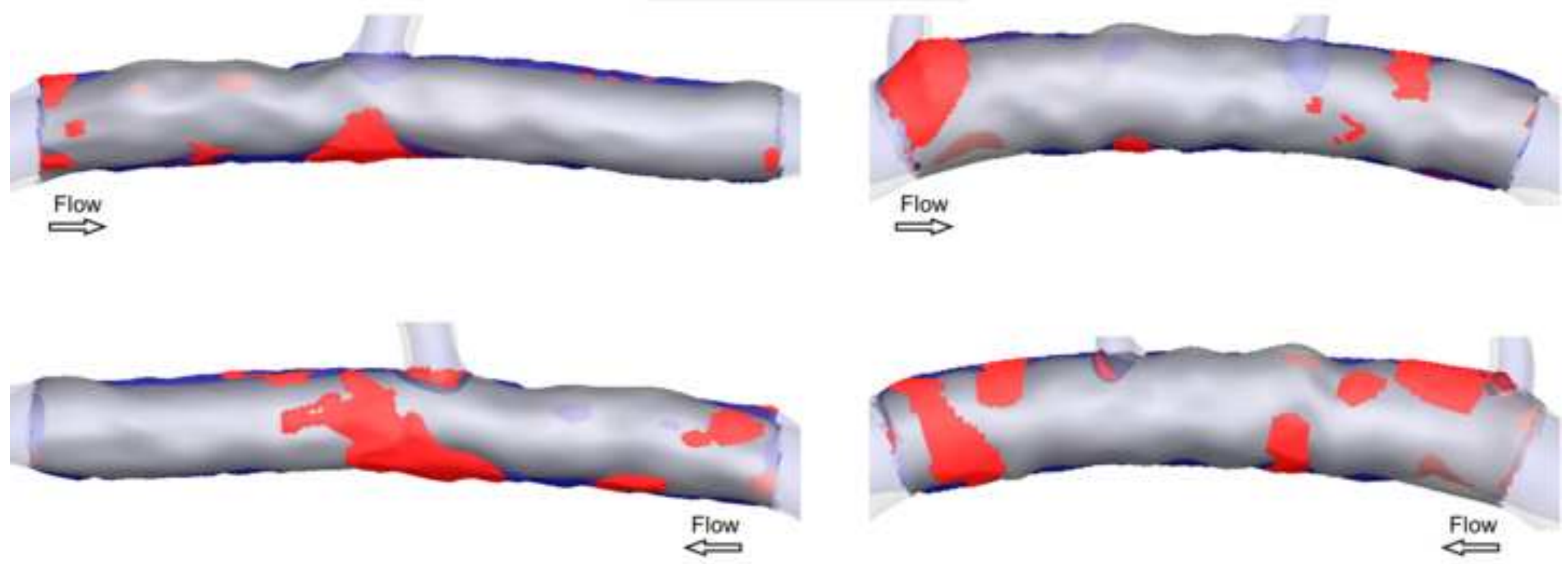
A) Xience Prime

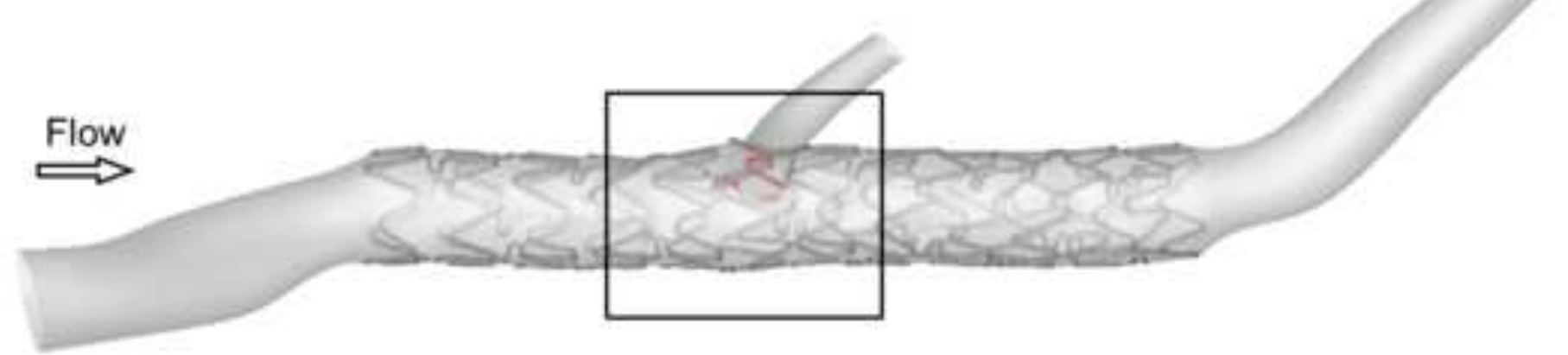

B) Nobori
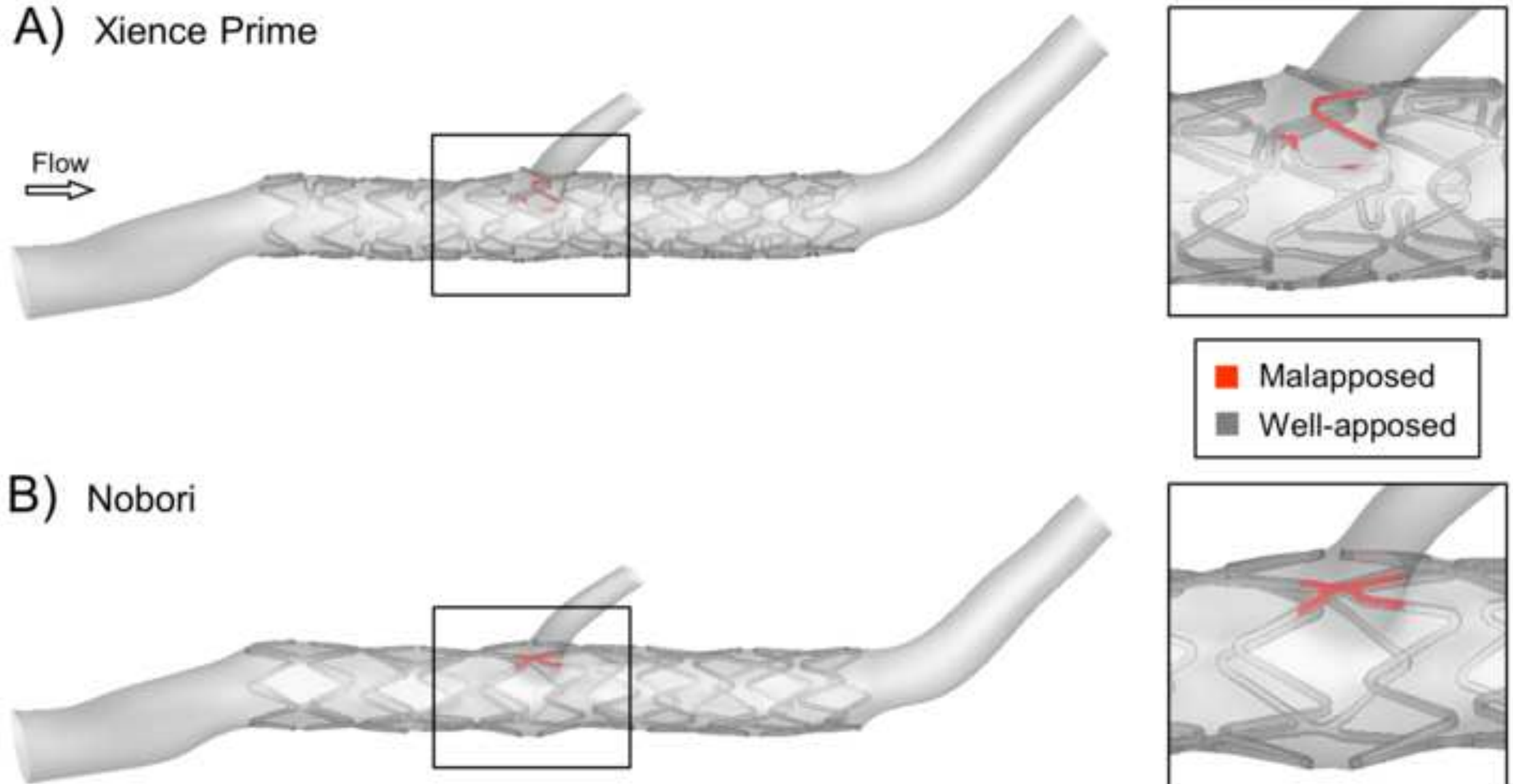

- Malapposed

E Well-apposed

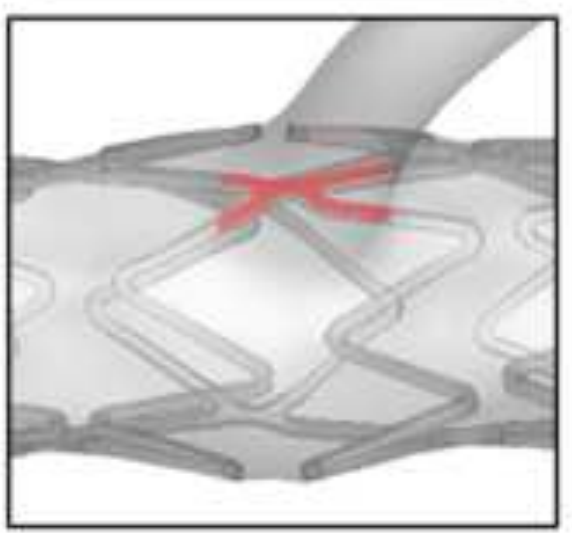


A) Nobori - position A

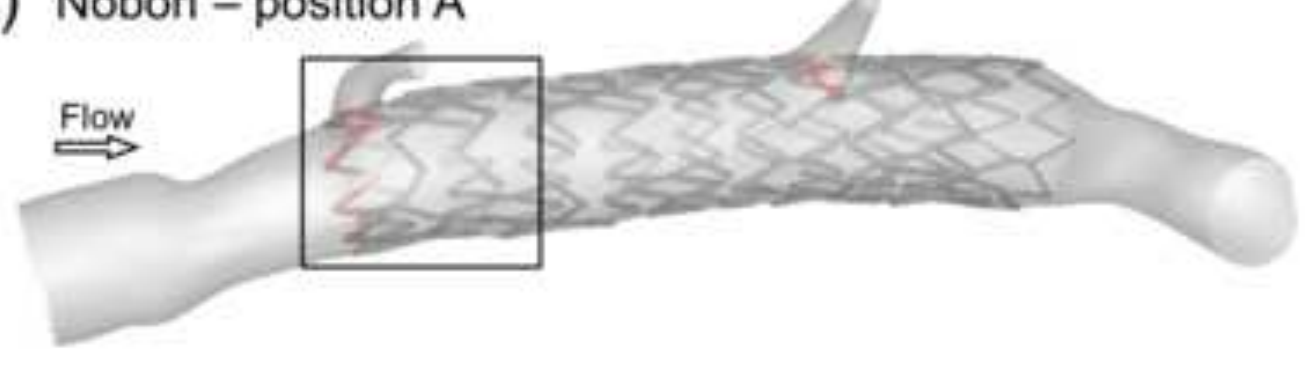

B) Nobori-position B

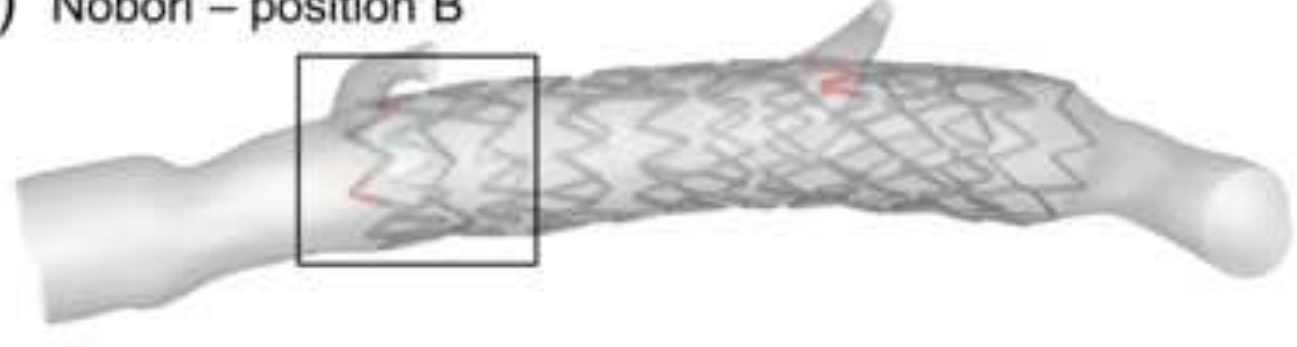

C) Nobori-position C

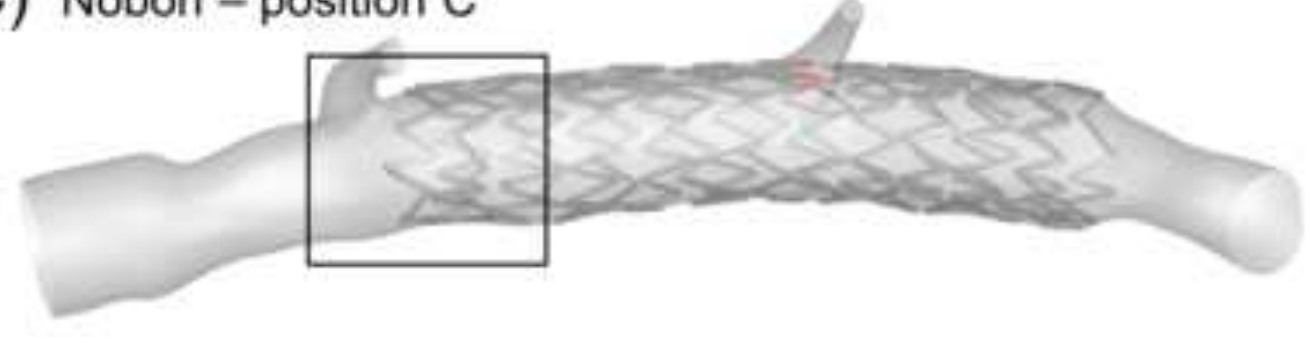

D) Xience Prime - position B

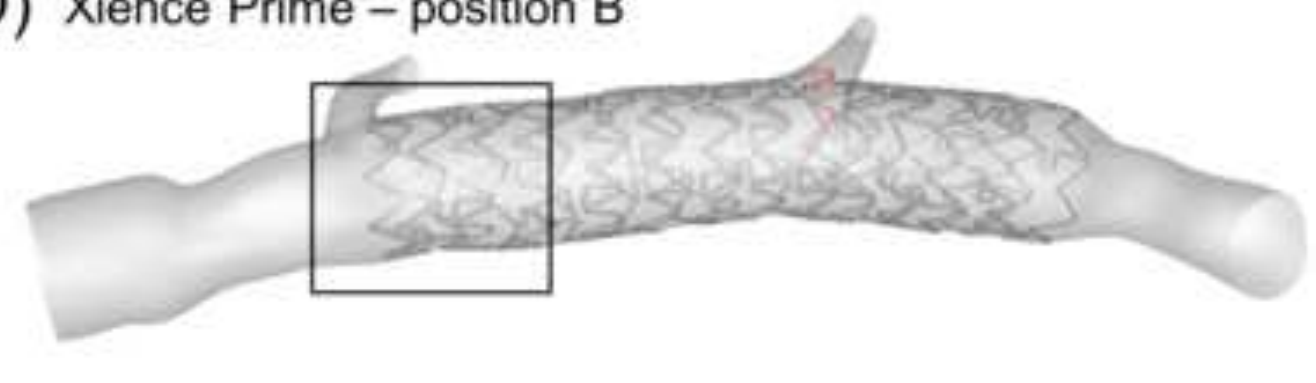

E Malapposed

E Well-apposed
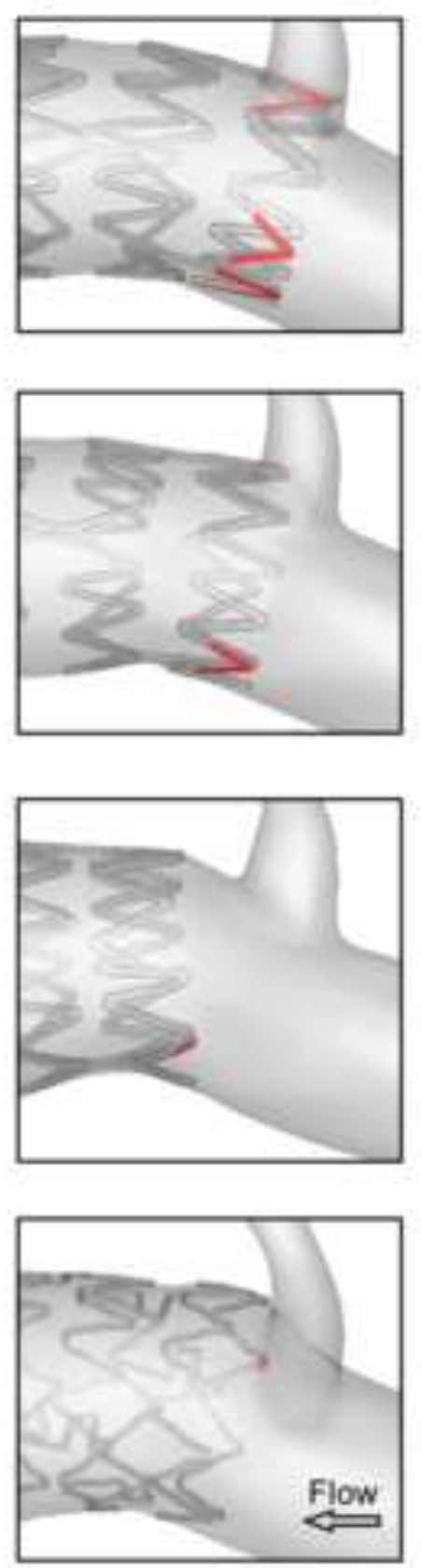

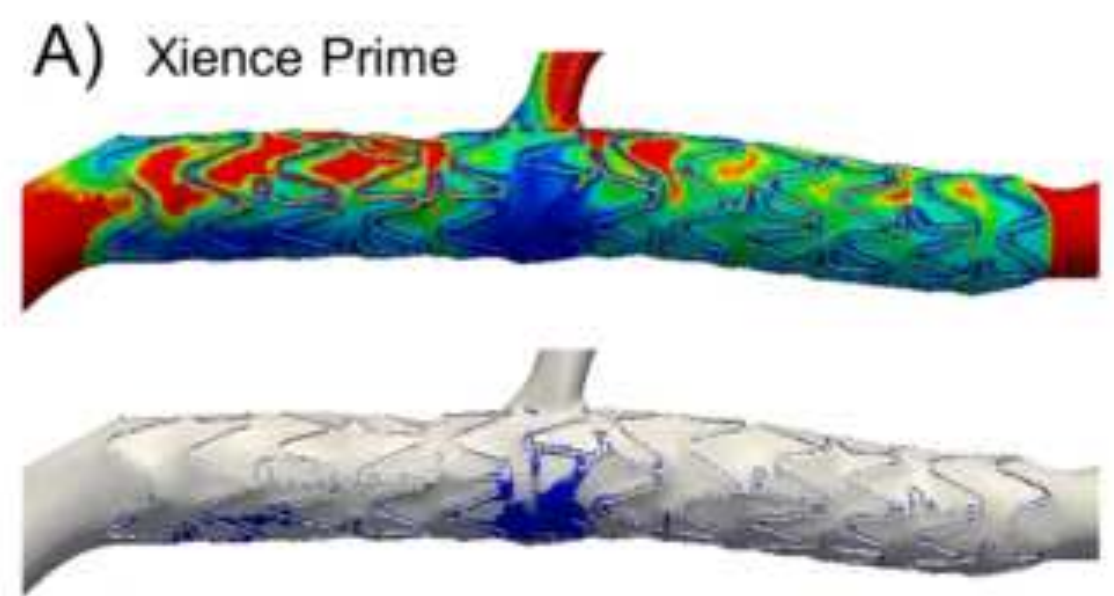

Flow

B) Nobori
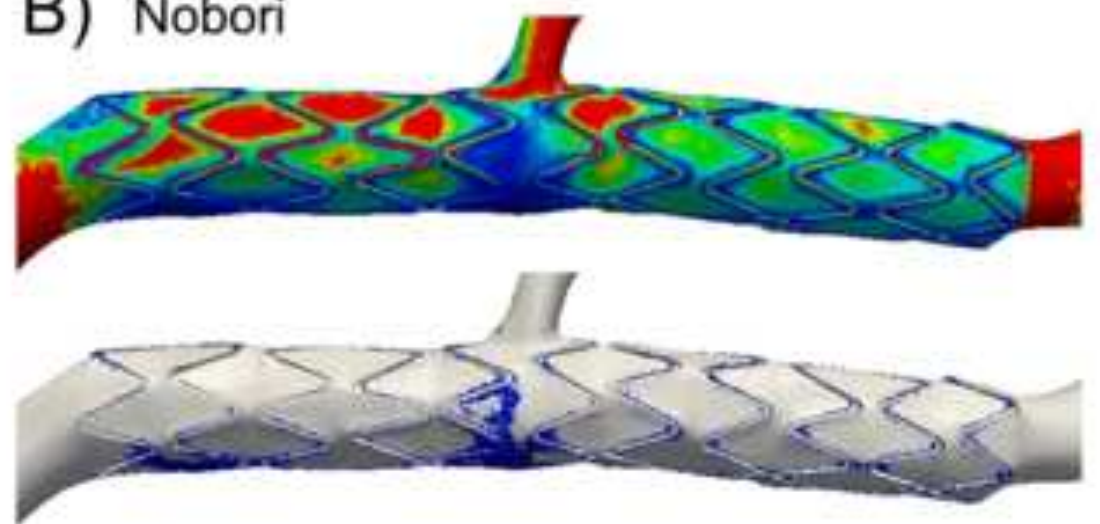

Flow
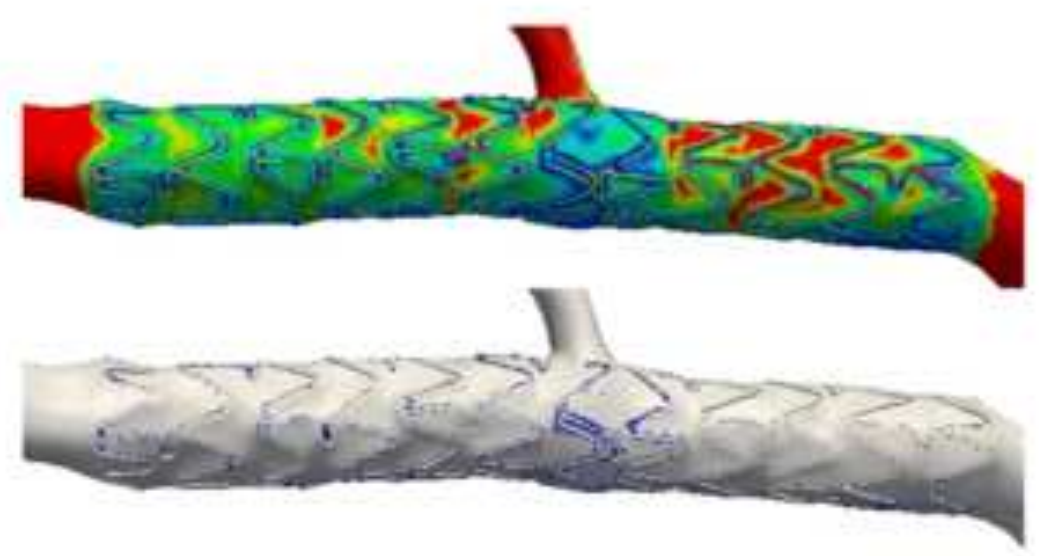

Flow
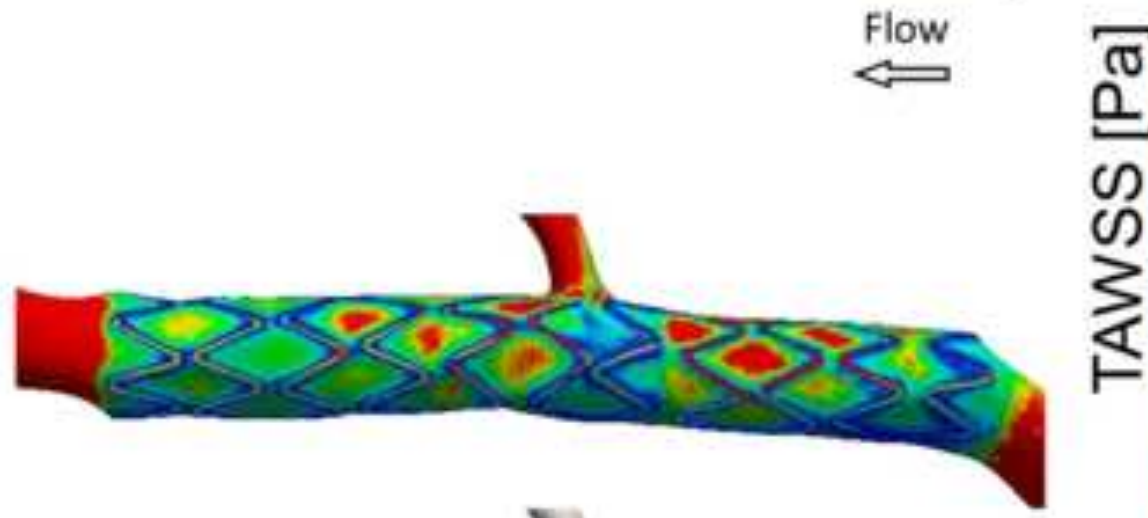

()

क

$\underset{1}{\lessgtr}$
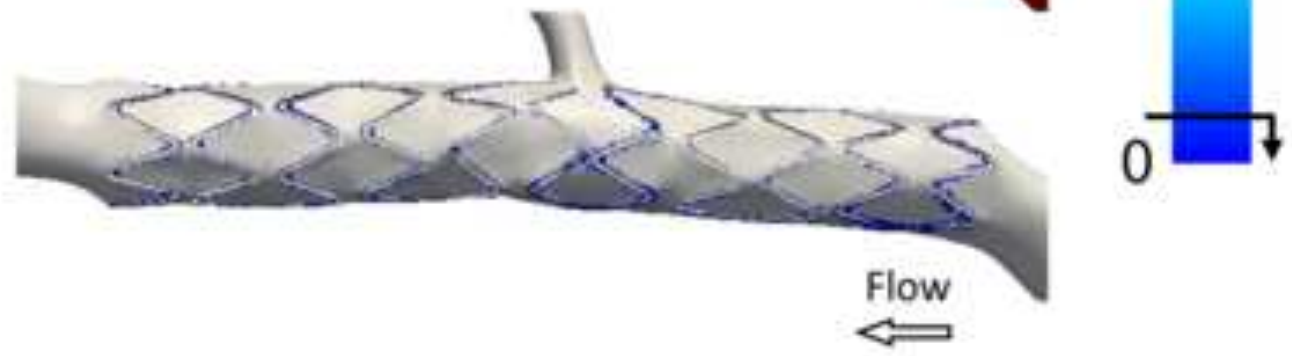

$\Longrightarrow$

Flow 


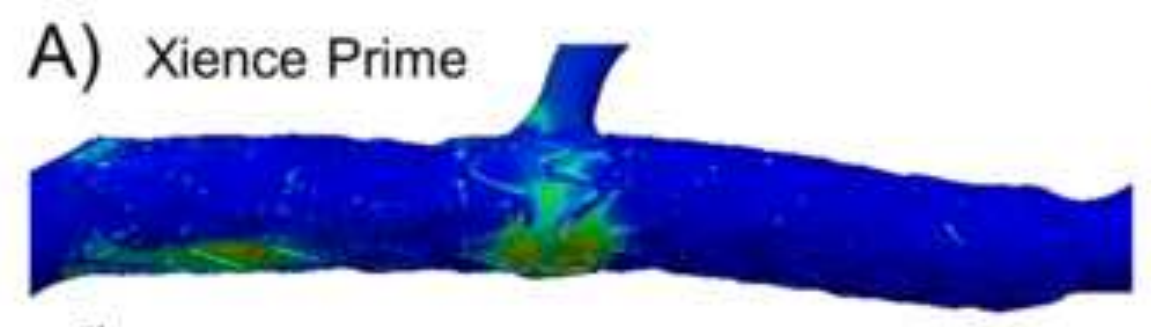

Flow

B) Nobori

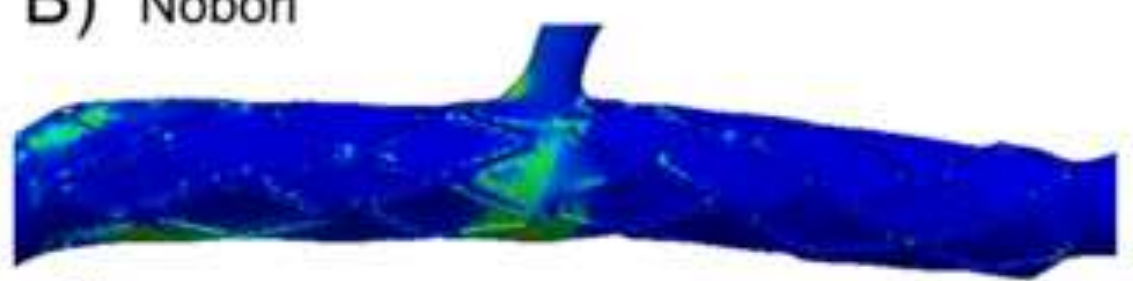

Flow

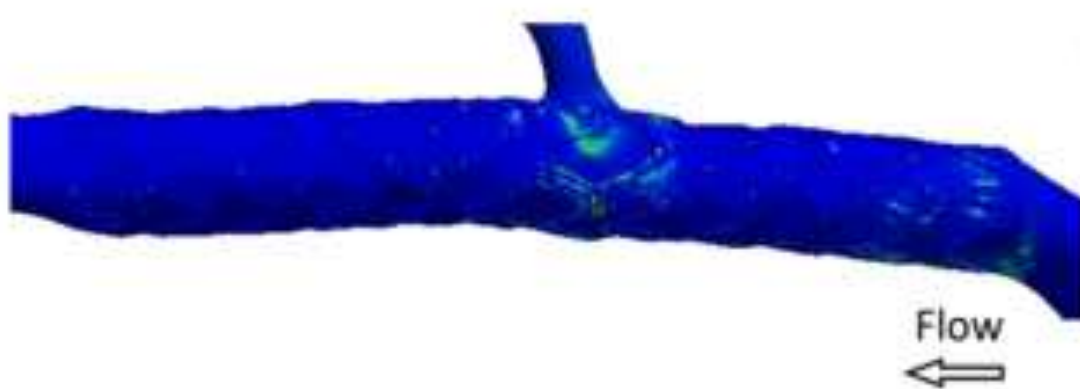

0.5

ऍ

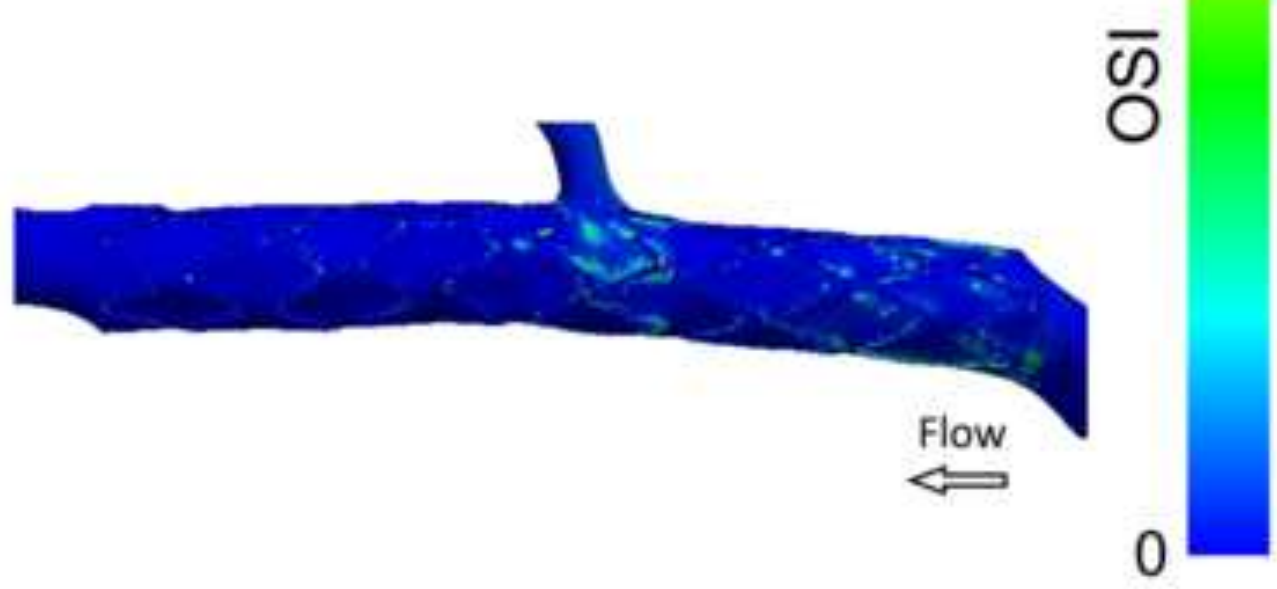


A) Nobori
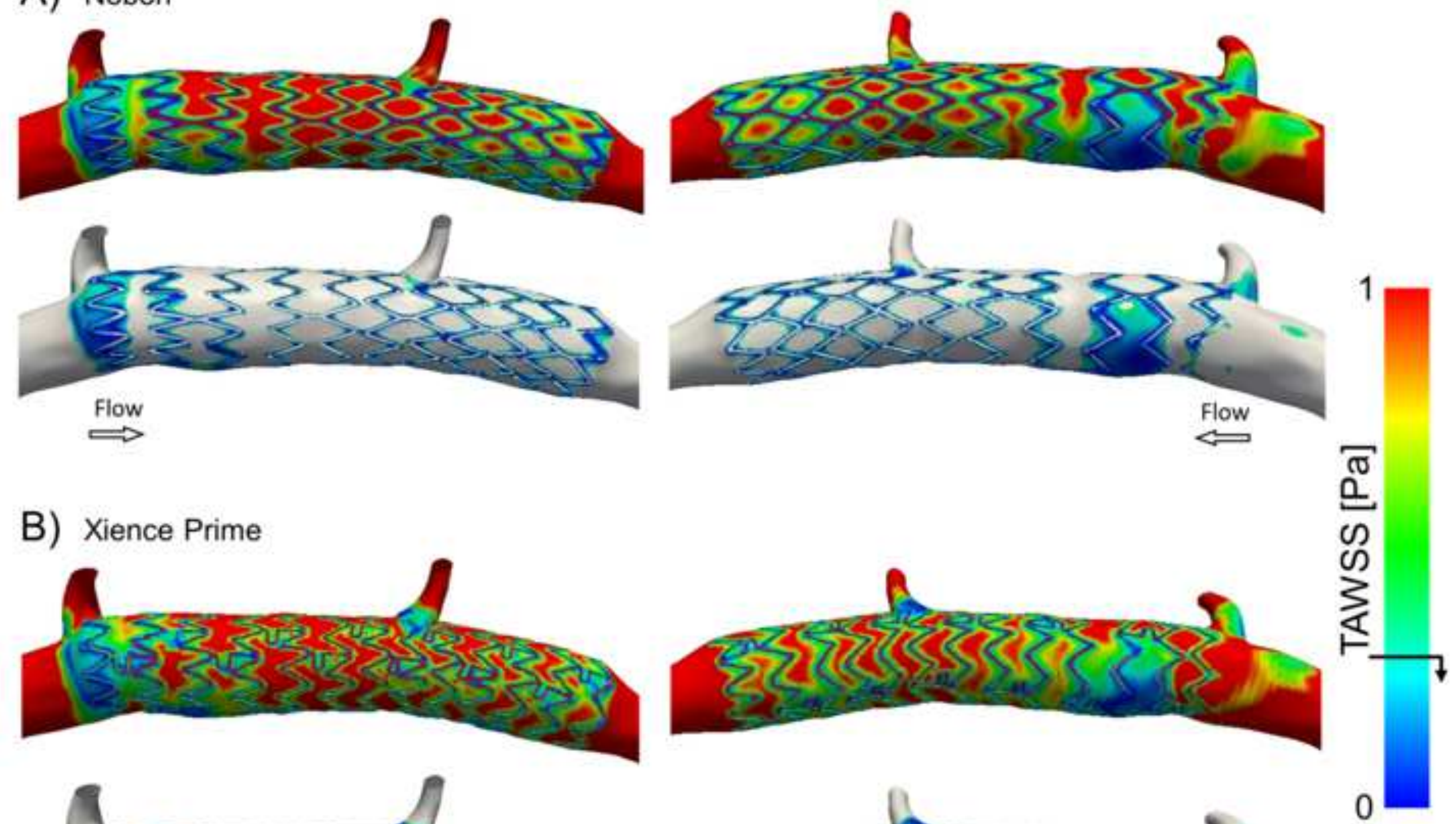

B) Xience Prime
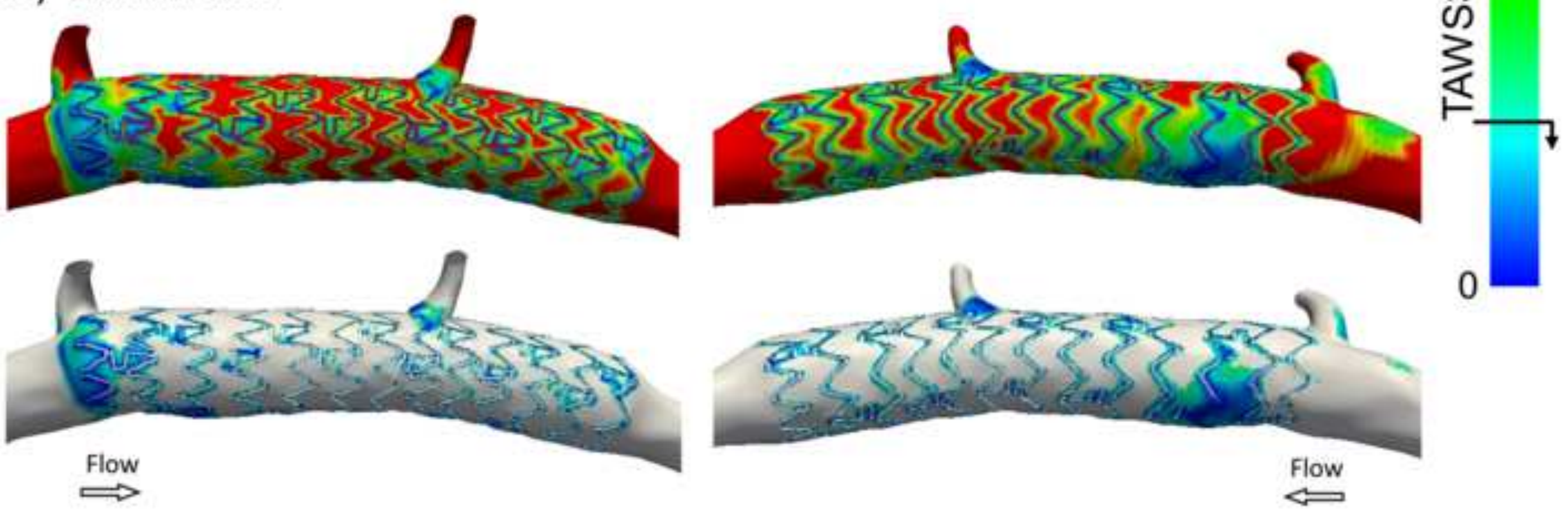


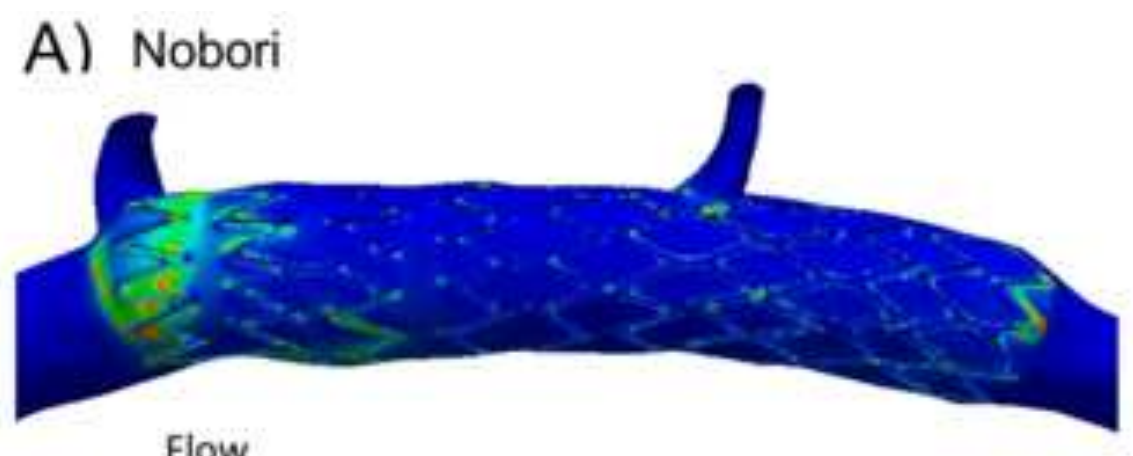

Flow

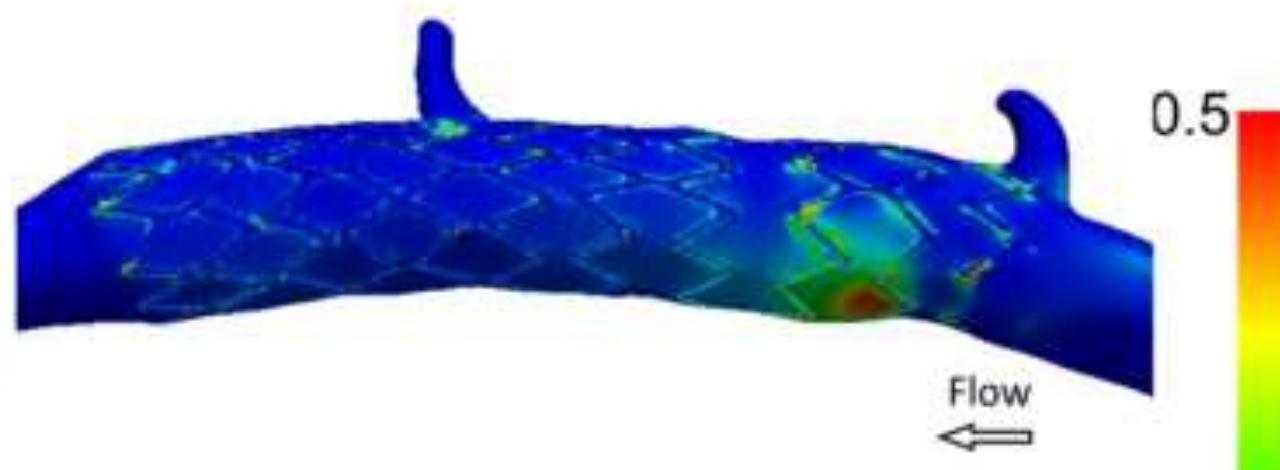

B) Xience Prime
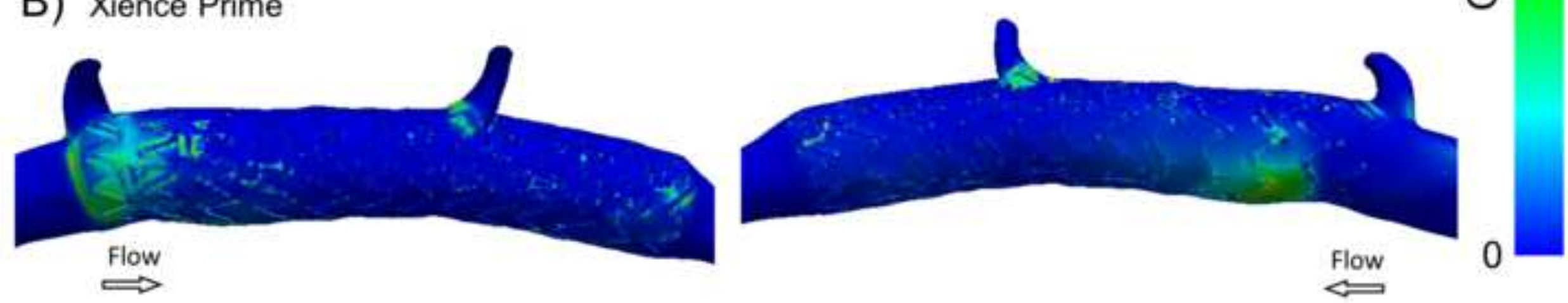